\title{
II. DEBATE
}

\section{LA PÓLIS, EL ESTADO Y LOS CIUDADANOS DE LA DEMOCRACIA ATENIENSE COMO UNA COMUNIDAD INDIVISA}

RESUMEN: En este artículo se analizan los recientes debates (junto con algunas de sus derivaciones) acerca de la operatividad del concepto de Estado para caracterizar a la pólis griega en general y a la ciudad democrática de Atenas en particular. En segundo lugar, se señalan algunos límites con los que los historiadores se han topado al intentar caracterizar, alternativamente, a la pólis democrática ateniense como una sociedad "con" Estado y "sin" Estado. Finalmente, se recogen los aportes de la antropología política y se exploran sus potencialidades para pensar al grupo de los ciudadanos como una comunidad indivisa en la que el poder resultaba elidido en tanto operaban diversos mecanismos que buscaban evitar el desarrollo de una fractura permanente entre gobernantes y gobernados.

PALABRAS CLAVE: Estado; Pólis; Atenas; Democracia; Antropología.

ABSTRACT: This paper looks at the recent controversy (with some of its ramifications) about the usefulness of "State" as a concept for the Greek polis in general and for the Athenian democracy in particular. Secondly, some limits of understanding Athenian democratic polis as a society "with" or "without" State are pointed out. Lastly, contributions from political anthropology are taken into account in order to suggest that the Athenian citizens were an undivided community in which power was elided because of the working of some devices that operated to avoid the development of a permanent breakup between rulers and ruled.

KEYWORDS: State; Polis; Athens; Democracy; Anthropology.

${ }^{1}$ Universidad Nacional de General Sarmiento / Universidad de Buenos Aires / Programa PEFSCEA / Instituto de Historia Antigua y Medieval "Prof. José Luis Romero" (FFyL-UBA), CONICET, Buenos Aires, Argentina. E-mail: diegopaiaro@hotmail.com 


\section{La “Crisis" del Estado y la Ciudad Griega}

Si bien se trata de una temática historiográfica clásica, la cuestión del Estado y lo estatal se encuentra actualmente, y desde hace cierto tiempo, en el centro de la escena. La reflexión sobre estos temas se ve hoy en día impulsada tanto por aquellos que piensan que asistimos al crepúsculo y la extinción del Estado - o, al menos, del Estado-nación como su principal forma - como por quienes ven, por el contrario, un desarrollo exponencial de su presencia, funciones y capacidades. De acuerdo a la perspectiva de algunos pensadores, la etapa histórica actual se caracteriza - y diferencia radicalmente del pasado - por desenvolverse bajo lo que ha sido denominado como una verdadera crisis y ocaso del Estado. Como producto de la desterritorialización de la riqueza, de la pérdida del poder soberano estatal frente a los flujos financieros internacionales pero, fundamentalmente, del agotamiento del lazo social que el imaginario y la subjetividad estatal representaban, se ha planteado que, por primera vez, estaríamos en condiciones de "pensar sin Estado" puesto que el Estado - si bien no habría desaparecido como "cosa” objetiva - ya no estaría (pre)supuesto y habría perdido ese lugar de articulador simbólico que gozaba antaño (Lewkowicz, 2004). A la vez, desde perspectivas menos rupturistas, otros coinciden en que, al menos, asistimos a la desestructuración de un tipo particular de Estado: desde la década de 1980, el denominado Estado de Bienestar se encontraría en un proceso de retracción, desorganización y reconfiguración aún vigente e inconcluso (Offe, 1990; Jessop, 1999) que llevaría, inclusive, a la crisis por obsolescencia del Estado-nación (Ohmae, 1995) o a la pérdida y reconfiguración de algunas de sus capacidades soberanas (Sassen, 1996; Strange, 1996). Finalmente, hay quienes conciben que la pretendida pérdida del poder estatal se trataría, en verdad, de un "mito" (Weiss, 1998) y, más aún, se ha llegado a postular que asistimos a una extralimitación excepcional de las funciones y los poderes del Estado en el que el "estado de excepción” se constituiría en la norma que rige los comportamientos políticos y gubernamentales contemporáneos (Agamben, 2005). ${ }^{2}$

Más allá de estos (y otros) distintos posicionamientos, lo cierto es que, los procesos históricos y de reflexión sobre lo estatal señalados no podrían haber pasado

\footnotetext{
2 Para una puesta al día de estos debates, puede ser de interés la consulta del trabajo monográfico de Portinaro (2003). El libro de Sørensen (2010) plantea un interesante balance de las controversias existentes entre las perspectivas del "repliegue" del Estado y los puntos de vistas "estado-céntricos" en la que se señalan las fortalezas y debilidades de cada postura.
} 
desapercibidos ni dejado de impactar en las formas de hacer historia. 3 La supuesta "crisis" del Estado se ha mostrado, en definitiva, como un campo fértil para su indagación histórica. No en vano, como disciplina científica, la ciencia histórica nació, fundamentalmente, como un análisis sobre los Estados, sus relaciones externas, sus evoluciones, sus diseños institucionales y sus agentes principales. Paradójicamente (o no tanto), 4 en el ámbito de los estudios clásicos y en particular en las investigaciones sobre la pólis griega antigua, esta llamada "crisis del Estado" ha sido el contexto que permitió que se desarrolle en particular desde la década de 1990 un vigoroso debate acerca de cómo entender la relación entre la ciudad y el Estado, es decir, acerca de si el concepto Estado resulta útil para analizar la realidad histórica griega y si la pólis, especialmente la democrática ateniense, puede pensarse como una sociedad estatal o como una comunidad carente de Estado. 5

Para el caso de las ciudades del mundo griego antiguo, debemos decir que, si bien la pregunta acerca del carácter estatal de la pólis no fue formulada explícitamente de modo recurrente hasta hace relativamente poco tiempo, tradicionalmente se ha pensado a éstas como sociedades estatales. ${ }^{6}$ La naturalización de tal operación de pensamiento llegó al punto que, comúnmente y sin mayores cuestionamientos, en el pasado pero también en la actualidad se utilizaron y se continúan utilizando términos como Estado o, en particular, ciudad-estado - inventado en 1840 por el estudioso danés Johan N. Madvig (Glassner, 2004, p. 35) - para traducir aquello que las fuentes antiguas llamaban pólis. En efecto, la amplia difusión del concepto de ciudad-estado en sus distintas formas idiomáticas, inglés: city-state, francés: cité-État, alemán:

3 Cf. por ejemplo el trabajo de Campagno \& Lewkowicz (2007) en el que se analiza cómo el agotamiento del Estado-nación impacta en la disolución del objeto unificado de la Historia.

4 Como ha afirmado Guery (1997, p. 233) en un artículo sobre cómo la "crisis del Estado" impactó en las prácticas historiadoras, “S'il existe un objet privilégié d'histoire, en ce temps de crise, c'est bien l'Etat!". Por su parte, Bringing The State Back In era la propuesta, ya a mediados de la década de 1980, de Evans, Rueschemeyer y Skocpol (1985).

$5 \mathrm{Al}$ respecto, según Manville (1994, p. 28), si bien no se podría afirmar que el Estado-nación estaba desapareciendo a mediados de la década de 1990, al menos se veía sometido a una fuerte presión en un contexto signado por la globalización económica en el que las fronteras territoriales se veían desafiadas por los movimientos cada vez más acelerados de poblaciones e información. Este contexto es, de acuerdo a la perspectiva del autor, el responsable de que opere un cambio en el paradigma acerca de cómo entender a la ciudadanía ateniense. Se daría así una transición desde el viejo paradigma "moderno e inorgánico" que pensaba a la ciudadanía como un producto del ordenamiento legal y en oposición al Estado hacia un nuevo paradigma "premoderno e inorgánico" en el cual no se distingue ya demasiado la esfera pública de la privada, la sociedad del Estado y este último ya no existe como un ente abstracto y autónomo separado de la ciudadanía.

${ }^{6}$ Los títulos de dos de los trabajos clásicos sobre las instituciones políticas griegas - el de Georg Busolt (Griechische Staatskunde, 1920-1926) y el de Victor Ehrenberg (The Greek State, 1960) - muestran el consenso acerca del carácter estatal de la pólis que se desarrolló entre los clasicistas e historiadores de la Antigüedad durante el siglo XIX y buena parte del XX (Zuiderhoek, 2017, p. 151). 
Stadtstaat, etc. - para referirse a las póleis de la Antigua Grecia marca la temprana tradición de conceptualizar a dichos agrupamientos políticos bajo el paradigma de la estatalidad.7 Sin embargo, es necesario plantear que en muchos casos se trataba de una operatoria dictada más por la difusión de cierto sentido común estatalista que por una reflexión en profundidad sobre la cuestión. ${ }^{8}$ Sentido común propio de una época en la el uso de la categoría Estado se encontraba naturalizado y su aplicación a las distintas sociedades históricas generalizado (incluso allí donde se buscaba argumentar su inexistencia). Es el cuestionamiento de dicho sentido común el que, en buena medida, enmarca las actuales indagaciones acerca de cómo caracterizar a la antigua pólis griega. 9

Atenas, ¿con o sin Estado?

Ahora bien, frente a ese predominio y naturalización de lo estatal, la "crisis" a la que nos hemos referido en el apartado anterior trajo aparejado el hecho de que, de

\footnotetext{
7 Recientemente Zuiderhoek (2017, p. 149) ha explicado esta cuestión: "This ancient view of the city (polis/civitas) as a community of citizens and their households is an uncomfortable one for modern commentators. It does not match very well the modern connotations of common political concepts (which, ironically, in their original form were actually derived from ancient city-based political thought and practice) such as, say, politics, citizenship and republic. These are all concepts which, in modern parlance, tend to be associated with the state. Indeed, so natural is this association that many historians, political philosophers and other scholars, past and present, habitually tend to assume that the ancient city must indeed have been a state of some kind. Yet the uneasiness never quite went away, and one can find it manifested in the admission, featured in virtually every modern Greek or Roman history textbook, that the use of the term 'city-state' (Stadtstaat, cité-état), while handy, does not quite catch what the ancients meant when they called a community a polis or a civitas".

${ }^{8} \mathrm{Al}$ respecto, Loraux (2007, p. 251) afirmó que "Si polis es el nombre griego de la colectividad política, el sintagma «ciudad-Estado» es el modo de traducción para los historiadores. Sintagma delicado: al adjuntar «Estado» a «ciudad» para evitar toda confusión de la polis con la ciudad, que es solamente el centro urbano, el historiador intenta por lo general precisar que la ciudad griega no es un Estado sino una colectividad que se expresa bajo el modelo del nosotros idealmente, - y así lo espera - en la realidad. [...] Desearíamos probablemente que el historiador demasiado sereno no fuera tan ingenuo de creer que el agregado de la palabra estado pueda alguna vez ser un gesto neutro". Cf. Osborne (1985, p. 8) que destaca el state de city-state es "misleading" y que, sin mayores especificaciones, un uso tan "innocent" dista mucho de ser claro. Como ha argumentado Gallego (2011, p. 194-197, 2017, p. 232-238), esta asociación de la pólis con el Estado (bajo el paradigma del concepto de "ciudad-estado") surgía no tanto de una reflexión sobre las características estatales de la ciudad antigua (o su ausencia) sino, más bien, por encontrarse vigente y arraigado en el pensamiento y en el sentido común la idea de que el Estado constituye el factor fundamental de cohesión de las sociedades; se trataría, en definitiva, de una "condición de época" de pensar "con Estado" solo superada muy recientemente con el contexto de crisis actual que permitiría, "pensar sin Estado" (Lewkowicz, 2004). Sin embargo, lo anterior no supone que no se hayan realizado esfuerzos importantes (aunque relativamente recientes) por clarificar el uso histórico de la categoría Estado (por ejemplo, Sakellariou, 1989) y "ciudad-estado" - ver al respecto, entre muchos otros, los trabajos reunidos por Griffeth \& Thomas (eds. 1981); Molho, Raaflaub \& Emlen (eds. 1991); Nichols \& Charlton (eds. 1997); Hansen (ed. 2000 y ed. 2002) o las síntesis de Burke (1986) y Parker (2004) y la discusión heurística general planteada por Glassner (2004) -; solo nos interesa marcar aquí esta disposición casi "natural" de identificar a las póleis con el Estado.

9 En lo que sigue volvemos sobre algunas argumentaciones que hemos desarrollado más extensamente en otros lugares: Paiaro (2011a, 2012a, 2014).
} 
un tiempo a esta parte, se haya venido poniendo en entredicho, desde diferentes ángulos y a partir de diversas perspectivas, aquella identificación de la pólis con el Estado que por tanto tiempo había resultado "natural" y no cuestionada. En cierta medida, la perspectiva de Starr (1986, p. 36, 44-45) marca esa tensión propia de una postura transicional ya que si bien reconoce diferencias entre la pólis y el Estado, le resulta poco factible abandonar el paradigma estatal: por un lado, destaca que la ciudad griega antigua no constituyó nunca esa entidad abstracta que caracterizó al Estado desde Maquiavelo en adelante pero, por otro lado, considera que "one cannot avoid the term «state» in a political analysis" (p. 36) de la ciudad helena. De alguna manera, la pólis no se parecería al Estado pero resultaba imposible pensarla - dada su dimensión política - más allá del paradigma estatal.10

La definición aristotélica según la cual "la ciudad, en efecto, es una cierta multitud de ciudadanos [he gàr pólis politôn ti plêthós estin]” (Pol.1274b41) o, en el mismo sentido, "la ciudad es una cierta comunidad, y es una comunidad de ciudadanos en un régimen [koionía politôn politeías]" (Pol. 1276b1-4) junto con otras afirmaciones que proponían que "los hombres son la ciudad [ándres gàr pólis]" (Thuc. $7 \cdot 77.7$ ) ${ }^{11}$ se encontraban por detrás de esta dificultad de asimilar a la ciudad griega con el Estado. Ni las definiciones de Aristóteles ni la idea de que los hombres constituyen a la ciudad permiten pensar a la pólis como lo hacemos con el Estado moderno, es decir, como un ente abstracto, autónomo, separado de (e incluso opuesto a) la sociedad (Osborne, 1985, p. 8-9). Concebimos al Estado como a una maquinaria independiente de la voluntad, los deseos y las acciones de cada uno de aquellos que habitan en el territorio que se encuentra bajo su soberanía. Frente a los griegos que pensaban a la pólis bajo la idea del "nosotros", 12 en la modernidad se identifica en el Estado a un "otro" frente al

\footnotetext{
${ }^{10}$ Por su parte, a la pregunta acerca de qué tienen en común la pólis y el Estado, Meier (1985, p. 28-29) respondía que "nada, indudablemente, excluyendo el hecho de que también ella constituye una unidad política" - y aquí vemos en última instancia la dificultad de pensar la política por fuera del Estado - y, en consecuencia, proponía separar conceptualmente a la pólis del Estado.

${ }^{11}$ Hay una serie de otras fuentes que se expresan en un sentido similar: Alceo (112.10 LP), Esquilo (Pers. 349); Sófocles (OT 53-7); Heródoto (8.100.2). Cf. Longo (1974, 1975); Loraux (1993, p. 282-296); Canfora (1993, p. 154-157); Paiaro (2012a, p. 52-54).

12 Anderson, G. (2009) ha argumentado en sentido opuesto al plantear que la pólis funcionaba y era percibida como una entidad abstracta y autónoma (personae fictae) a la que denomina Demos-State y diferencia del dêmos constituido por "the aggregate of living, breathing, «natural» persons who made up the actually existing dêmos at any given time" (p. 19). Cf. sin embargo, la postura de Buis (2015, p. 77-123) en la que se argumenta, sólidamente desde nuestro punto de vista, en contra de la idea del desarrollo de las póleis como "sujetos" en el sentido de personas jurídicas en el plano del derecho internacional. En la misma línea, Hansen (1989a, p. 17-21, 1998, p. 67-73) había afirmado que el término pólis podía ser usado para referirse a un poder público trascendente de un modo similar al que el concepto moderno de Estado es utilizado en la actualidad.
} 
cual existen derechos específicos que protegen a los ciudadanos. ${ }^{13}$ Así, en el pensamiento moderno el Estado es tratado como un "dios mortal” (Hobbes, 1980. p. 141), "el más frío de todos los monstruos fríos" (Nietzsche, 1999, p. 41) y una "máquina" brutal y opresiva (Lenin, 1997). En el pensamiento griego, sin embargo, sería infructuosa la búsqueda de un imaginario parecido para referirse a la pólis (Anderson, G., 2009, p. 1).

Paralelamente, una línea interpretativa elaborada algunas décadas antes y vigente durante bastante tiempo partía de la idea de que lo que caracterizaba a la pólis era que en ella no se podía distinguir entre el Estado y la Sociedad. En este sentido, Ehrenberg (1960, p. 88) afirmaba que "the Polis was the state of the politai, the citizens" algo que determinaba la "identity of state and society, at least as far the citizens alone were concerned” (p. 89). Lo anterior suponía una contradicción - nunca comprendida por los griegos (Vernant, 1992, p. 57-58, n. 10) - entre el carácter unitario del Estado y la pluralidad de la Sociedad basada en una gradación de órdenes sociales heterogéneos. Siguiendo estos desarrollos, Anderson, P. (1997, p. 38) sintetizó la cuestión para la democracia ateniense de la siguiente manera:

...la naturaleza democrática de la polis ateniense - cuyo principio no era la representación, sino la participación directa - imposibilitaba la creación de una maquinaria burocrática capaz de someter por medio de la coerción administrativa a un extenso imperio territorial. Apenas existía un aparato de Estado separado o profesional en la ciudad, cuya estructura política se definía esencialmente por su rechazo de cuerpos especializados de funcionarios - civiles o militares - situados aparte de los ciudadanos ordinarios: la democracia ateniense significaba, precisamente, el rechazo de semejante división entre «estado» $\mathrm{y}$ «sociedad».

Esta indistinción entre el aparato gubernamental y el cuerpo de los ciudadanos de la pólis no sólo implicó un problema para la capacidad de los griegos de distinguir entre Estado y Sociedad sino que también fue de difícil aprehensión por parte de la teoría del Estado clásica (Routledge, 2014, p. 75-76). Si bien la pólis ateniense no habría tenido existencia más allá de la auto-organización de la ciudadanía, ${ }^{14}$ carecía de un aparato burocrático que pudiera alienar la capacidad de toma de decisiones del

\footnotetext{
${ }^{13}$ Sobre la posibilidad de pensar el problema de los derechos del individuo frente al Estado en la situación ateniense: Sancho Rocher (2011a, 2011b); cf. el debate entre Hansen (1989a, 1996) y Ober (1996, p. 161-187, 2000).

14 Como ha afirmado Castoriadis (1997, p. 203), "En el mundo antiguo, no hay Estado como aparato o instancia separada de la colectividad política. El poder, es la colectividad misma que lo ejerce".
} 
pueblo y establecer una base independiente de intereses y capacidades y, en consecuencia, era cualquier cosa menos autónoma en el restringido sentido empírico del término, sin embargo, como ha planteado Rosenberg (1994, p. 79), "yet it talks like a state!"15

Por otro lado, en una perspectiva que buscaba proponer un esquema general de interpretación social e histórica capaz de comprender a múltiples sociedades de diversas coordenadas espaciales y temporales, Gellner (1991, p. 23-24) propuso la noción de "Estado agrario alfabetizado" en el que

la clase dirigente está formada por una pequeña minoría de la población estrictamente separada de la gran mayoría de los productores agrícolas directos o campesinos. En general, su ideología, más que atemperar, acentúa la desigualdad de clase y el grado de alejamiento del estrato dirigente. Este, a su vez puede dividirse en cierto número de capas más especializadas: guerreros, sacerdotes, clérigos, administradores, ciudadanos. [...] Debajo de la minoría horizontalmente estratificada que está en la cúspide existe otro mundo, el de las pequeñas comunidades separadas entre sí verticalmente que forman los miembros legos de la sociedad. [...] Las preocupaciones del estado no van mucho más allá de recaudar impuestos y mantener la paz...

Sin embargo, esta caracterización, sería inaplicable al "milagro" de la Grecia Antigua en tanto que allí no se desarrolló lo que denomina la "dominación militarclerical": las "ciudades-estado" griegas se habrían caracterizado por "un grado de diferenciación cultural horizontal bastante bajo" (Gellner, 1991, p. 28) y por ser "sociedades libres de dominación" (Gellner, 1994, p. 23; cf. Herman, 1987, p. 162-165; Morris, 1991, p. 46-49, 1997, 2009, p. 136-141; Berent 2000a, p. 259-260, 200ob, p. 16-17, 2004, p. 112-113).

Algunos autores tendieron a sacar conclusiones más radicales en relación a estas incongruencias entre la pólis griega antigua, las sociedades agrarias preindustriales y el concepto moderno de Estado. Por ejemplo, para Osborne (1985, p.7) si bien es cierto que Atenas "did have some sort of central government”, allí "there was no equivalent to the authority of the state, no attempt to monopolize the use of the force", monopolio en el uso de la fuerza que es considerado como una "defining feature

15 Morris (1987, p. 3) afirma que "the ethic of a polis was almost a stateless state, autonomous from all dominant-class interests by being isomorphic with the citizen body. The citizens were the state". Cf. Ober (1996, p. 163); Wood (1996, p. 128); cf. Rahe (1994, p. 16) para quien, directamente, "just as there was no Greek state, so there was no civil society". 
of the state". Aquí, a pesar de no citarla directamente, ${ }^{16}$ Osborne estaba haciendo referencia a la definición clásica de Weber (1964, p. 1056-1057) - a la que Bobbio (1989, p. 91) definió como la communis opinio - que en gran medida constituyó el punto de apoyo sobre el que giró y continúa girando la polémica:

el Estado es aquella comunidad humana que en el interior de un determinado territorio - el concepto del «territorio» es esencial a la definición - reclama para sí (con éxito) el monopolio de la coacción física legítima. [...] El Estado, lo mismo que las demás asociaciones políticas que lo han precedido, es una relación de dominio de hombres sobre hombres basada en el medio de la coacción legítima (es decir: considerada legítima).

En un sentido similar a Osborne, aunque no descartando totalmente el uso del concepto de Estado - caracteriza a las póleis como Estados que son "strikingly weak" (Morris, 2009, p. 136) -, Morris (1994, p. 44) afirmó que "modern definitions of the state emphasize a central monopoly of force, but in Classical Greece this was strictly circumscribed". Para el autor, siguiendo a Lisias (1.2), se puede pensar que la mayoría de las póleis permitían que los ciudadanos puedan incluso llegar a matar a otros ciudadanos para protegerse de determinados crímenes como el adulterio, el homicidio y cierto tipo de robos. Esto último se encontraba asociado al hecho de que no habrían existido en las ciudades griegas organismos de coacción permanentes con el objetivo de hacer cumplir las decisiones de los magistrados y desarrollar las funciones policiales. En consecuencia, "state authority rested to a remarkable extent on the willingness of individual citizens to fulfill their obligations, and did not constitute a power external to the citizens themselves". Es posible notar cierto grado de contradicción en esta postura en la cual el monopolio centralizado de la fuerza aparece como un elemento central de la definición de lo estatal y, a la vez que se minimiza la existencia de dicho monopolio, se concluye haciendo consideraciones acerca de las particularidades de la "autoridad estatal" (cf. Berent, 2004, p. 127). Sin embargo, el desarrollo del imperio habría llevado a Atenas a convertirse en "home to a ruling elite

\footnotetext{
${ }^{16}$ De hecho, Osborne (1985, p. 218, n. 29) lo hace a partir del prefacio elaborado por Radcliffe-Brown (1940, p. xiv) a African Political Systems cuando afirma que "In studying political organization, we have to deal with the maintenance or establishment of social order, within a territorial framework, by the organized exercise of coercive authority through the use, or the possibility of use, of physical force. In well-organized states, the police and the army are the instruments by which coercion is exercised. Within the state, the social order, whatever it may be, is maintained by the punishment of those who offend against the laws and by the armed suppression of revolt". Luego referencia el trabajo de Cherry (1978, p. 411) que, piensa, inspirado en Weber.
} 
interested in extracting taxes, maintaining the peace, and defending itself - that is, something Gellner would have immediately recognized as an agro-literate state" (Morris, 2009, p. 139).

Se podrían citar varias referencias bibliográficas (Manville, 1994, p. 23; Cartledge, 1999; Wood, 1996, p. 128; López Barja de Quiroga, 2012) de estudios que, desde hace ya cierto tiempo, cuestionan una simple identificación de la pólis ${ }^{17}$ con el Estado - ya hacia finales de la década de 1980, Hansen (1989a, p. 41, n. 126) afirmaba que "it is no longer fashionable to argue that the classical Greek polis was, essentially, a type of state" $-18 \mathrm{y}$, es probable que la cuestión se encuentre vinculada, como ha propuesto de modo general Bobbio (1989, p. 91-92), con la definición de Estado que los investigadores toman como punto de partida:

...la cuestión de si el Estado existió siempre o si se puede hablar de Estado solamente a partir de una cierta época es un asunto cuya solución depende únicamente de la definición del Estado de la que se parte: si se da una definición amplia o restringida. La preferencia por una definición depende de criterios de oportunidad y no de verdad [...] Quien considera como elemento constitutivo del concepto de Estado un determinado aparato administrativo y la realización de ciertas funciones que solo el Estado moderno desempeña, forzosamente deberá sostener que la pólis griega no es un Estado, que la sociedad feudal no tenía un Estado, etcétera.

A pesar de esta (obvia) dependencia de los aspectos vinculados a la definición conceptual expresada por Bobbio, lo cierto es que, tal cual lo ha mostrado Scheidel (2013, p. 7) en un exhaustivo trabajo reciente, - más allá de la gran variabilidad conceptual que había permitido a Easton (1981) distinguir al menos 140 definiciones de Estado - los diferentes abordajes de la problemática suelen ser, en mayor o en menor medida, deudores de los postulados de Weber (que hemos citado más arriba). ${ }^{19}$ De este modo,

\footnotetext{
${ }_{17}$ Algo similar tendió a pasar con la civitas romana; al respecto ver la argumentación y la bibliografía trabajada por Zuiderhoek (2017, p. 1154-1159)

18 Veinte años después, Anderson (2009, p. 1) reafirmaba esta postura para hablar de una amplio consensoun amplio consenso: "a broad consensus does appear to have emerged in recent years. A growing number of authorities now seem prepared to agree that the political structures in Classical poleis cannot be considered «states» in any conventional, full sense of the term". Cf. Harris (2013, p. 22).

19 Solo para citar algunos ejemplos: Sanderson (1995, p. 55-57) define al Estado como "a form of sociopolitical organization that has achieved a monopoly over the means of violence within a specified territory" (p. 56), monopolio que no debe ser necesariamente absoluto pero si suficiente para evitar las rebeliones contra el poder. Para Tilly (1993, p. 20) define a los Estados "como organizaciones con poder coercitivo, que son diferentes a los grupos de familia o parentesco y que en ciertas cuestiones ejercen una clara prioridad sobre cualquier organización dentro de un territorio". Mann (1991, p. 64), partiendo
} 
All these definitions coalesce around a number of key features: centralized institutions that impose rules, and back them up by force, over a territorially circumscribed population; a distinction between the rulers and the ruled; and an element of autonomy, stability, and differentiation. These distinguish the state from less stable forms of organization, such as the exercise of chiefly power. (Scheidel, 2013, p. 7)

Ahora bien, una serie de trabajos a cargo de Berent ${ }^{20}$ (1996, 1998, 2000a, 2000b, 2004, 2006) constituyen la crítica más sistemática y radical a la identificación de la pólis (y en particular de la ciudad democrática ateniense) con el Estado. Lejos de poder ser aprehendida por el concepto de Estado, para este autor la pólis se asemejaba a lo que los antropólogos definen como una "comunidad no estatal" (stateless community). ${ }^{21}$ Este tipo de comunidad se caracterizaría, haciendo un negativo de la definición de Estado de Weber que hemos citado más arriba, por la ausencia de una institución o clase que sea capaz de monopolizar los medios de coerción y el uso de la violencia: dicha violencia, en definitiva, se encontraría distribuida de modo más o menos equitativo entre los miembros armados o potencialmente armados de la sociedad. ${ }^{22}$ Para Berent, entonces, la cuestión primordial es la carencia de un aparato coercitivo: al no disponer las póleis de un ejército movilizado permanentemente, las milicias de ciudadanos no podían utilizarse para tareas de control social interno. Solamente las tiranías las utilizaron como fuerza policial y por ello constituirían un

de Weber, propone que "el Estado es un conjunto diferenciado de instituciones y de personal que incorporan la centralidad, en el sentido de que las relaciones políticas irradian hacia afuera para abarcar una zona territorialmente demarcada, sobre la cual reivindica el monopolio de la formulación vinculante y permanente de normas, respaldado por la violencia física”. Cf. inter alia Morris (1991, p. 40-41); Haldon (1993, p. 32-33); Hansen (2000, p. 13); Goldstone \& Haldon (2009, p. 6). El caso de Silver (2015, p. 4) es bastante particular ya que se diferencia al separarse del paradigma weberiano y adoptar una perspectiva de la economía neoclásica al definir al Estado como una empresa (firm): "«state» is defined as a specific kind of organization (a firm). Unlike mainly nonempirical approaches, the «state as a firm» perspective utilizes a neoclassical economic analysis with measurable demographic independent/explanatory variables to predict when states will be desired, formed, divided and discarded".

${ }^{20}$ Basados principalmente en su tesis doctoral dirigida por Cartledge (1999): The Stateless Polis: Towards a Re-Evaluation of the Classical Greek Political Community (Cambridge, 1994).

${ }^{21}$ Se trata, ciertamente, de una perspectiva muy polémica que ha cosechado un abanico de posicionamientos que van desde los adherentes totales o parciales a los detractores acérrimos. Ver, entre muchos otros, Cartledge (1999, 2005, 2009, p. 13-14); Faraguna (2000); Hansen (2002); Grinin (2004); van der Vliet (2005, 2008); Herman (2006, p. 216-257); Miyazaki (2007); Anderson (2009); Harris (2013, p. 21-59); Gallego (2017, p. 19-22).

${ }_{22}$ Berent (1996, p. 37, 1998, p. 333, 2000a, p. 258, 2000b, p. 2, 2004, p. 107-108, 2006, p. 141) refiere a los postulados tanto de Gellner (1991, p. 15-7) como la clásica distinción hecha por Fortes \& EvansPritchard (1940, p. 5-6) entre sociedades estatales y no estatales para el estudio antropológico de las poblaciones africanas. Cf. Anderson (2009, p. 3-4) quien critica a Berent al considerar que realiza una lectura incorrecta de la definición weberiana al confundir el monopolio efectivo en el uso de la fuerza con la pretensión del Estado de retener para sí mismo la capacidad legítima de autorizar su uso; en el mismo sentido, Ismard (2014, p. 507, n. 12). 
intento de centralizar los medios de coacción, es decir, de crear un Estado (cf. Morris, 1991, p. 48: "tyranny was the antithesis of the polis. It is no accident that most tyrants are credited with centralizing state power"; Finley, 1986, p. 33). Esta falta de instituciones centralizadas que hayan sido capaces de disponer del uso de la fuerza para ejercer la regulación social tendría como consecuencia directa que las póleis hayan tenido que recostarse en sus ciudadanos (politai) "privados” para el desempeño de aquellas tareas que constituirían las específicas del Estado. Frecuentemente, entonces, las ciudades habrían confiado en la iniciativa "privada" (self-help) de sus ciudadanos (apoyados por amigos, vecinos y familiares, pero no por funcionarios estatales) para investigar, detener, enjuiciar e imponer las decisiones de los tribunales.

Creemos importante detenernos en algunos aspectos de estos planteos que resultan de interés. En primer lugar, la pretendida debilidad del aparato coercitivo. Finley (1986, p. 32-33) se encargó de sintetizar la cuestión general para la ciudad antigua:

Toda actividad militar representaba poder en su sentido estricto de fuerza, ejercitado fuera. Nuestro interés, sin embargo, se concentra principalmente en el funcionamiento interno del estado. ¿Qué poder tuvo para hacer cumplir sus decisiones en los numerosos campos del comportamiento para los que estableció leyes? La antigua ciudad-estado no tuvo más policía que un relativamente pequeño número de esclavos, propiedad del estado, a disposición de los distintos magistrados, desde los arcontes y cónsules hasta los inspectores del mercado [...] Pero - y esto es crucial y excepcional - el ejército no estaba disponible para los deberes policiales a gran escala, hasta que la ciudad-estado fue substituida por una monarquía.

Herman (2006, p. 229; cf. 1994, p. 114) se propuso examinar el tema en profundidad para el caso de la democracia ateniense. De acuerdo a su análisis, quienes en la ciudad democrática desarrollaban tareas de tipo coactivas eran: los nueve arcontes y el secretario de los tesmótetas; los Once (héndeka) guardianes de la prisión y verdugos encargados de las ejecuciones; $y$, los denominados "arqueros escitas”. Bajo la autoridad de los pritanos, estos últimos son referidos en la documentación como toxótai ("arqueros", por su armamento), Scýthai (“escitas”, por su supuesto origen, a pesar de que su homogeneidad étnica no se puede afirmar de forma absoluta) ${ }^{23}$ o

\footnotetext{
23 De hecho, podría tratarse de una denominación tendiente a marcar su valoración negativa. Cf. Ismard (2015, p. 77); Lissarrague (1990, p. 130). El fragmentario Los Escitas de Sófocles podría haber tenido alguna influencia en la construcción arquetípica del escita como "otro".
} 
speusínioi (por su fundador, Speusinos). ${ }^{24} \mathrm{Si}$ bien es discutida la fecha exacta de su introducción - ya que tanto Andócides (3.3-7) como Esquines (2.172-4), que se basa en él, presentan serios problemas cronológicos -, sabemos que el cuerpo se constituyó a partir de una compra realizada por la ciudad entre el fin de las Guerras Médicas (479) y la Paz de Calias (449). ${ }^{25}$ En tanto es seguro que en su origen fueron trescientos, resulta probable que su número haya aumentado hacia finales del siglo V llegando a los mil o mil doscientos miembros. ${ }^{26}$ Dotados de distintas armas como el látigo, el arco y, posiblemente, un pequeño puñal, estos esclavos a los que el escoliasta de Los Acarnienses de Aristófanes denominó como demósioi hyperétai, phýlakes toû ásteos ${ }^{27}$ [“esclavos públicos, guardianes urbanos”] disponían de una importante capacidad coercitiva. Esta, se encontraba al servicio de llevar a cabo su principal métier: mantener el orden en las asambleas, los tribunales y demás reuniones públicas en el ágora; su participación en garantizar el cumplimiento de la ley, los arrestos de los criminales y el ejército es más discutida. ${ }^{28}$

Ante un aparato coercitivo rudimentario dadas las dimensiones de la población ateniense, 29 la cuestión que aparece inmediatamente es acerca de cómo hacía la pólis para que sus decisiones y leyes fueran respetadas, es decir, cómo se llevaba a cabo aquello que los especialistas del ámbito anglosajón denominan law enforcement. Por supuesto que la evasión se puede rastrear en la documentación;30 sin embargo, ¿por qué los condenados a la pérdida de sus propiedades, al exilio y hasta a la muerte

\footnotetext{
24 Pólux (8.131-2); Suda (s.v.: toxótai); Focio (s.v.: toxótai) y el escolio a Aristófanes (Ach. 54).

${ }^{25} \mathrm{Al}$ respecto, ver el completo tratamiento del tema por Couvenhes (2012). Cf. Hall (2006, p. 232-233); Ismard (2015, p. 77).

${ }^{26}$ Para el número de mil: Suda (s.v.: toxótai) y el escolio a Aristófanes (Ach. 54). Cf. Jacob (1928, p. 6472); Hall (2006, p. 233); Tuci (2005, p. 376); Couvenhes (2012, p. 103); Ismard (2015, p. 77).

27 Escolio a Aristófanes (Ach. 54).

${ }^{28}$ Cf. Berent (1996, p. 41); Hunter (1994, p. 143-149); Allen (2000, p. 40-46); García (2006, p. 201-216). Hansen (1991, p. 124) ha propuesto que los arqueros escitas no pueden asimilarse a una policía en el sentido moderno del término. Cf. las críticas de Grinin (2004, p. 127) y van der Vliet (2005, p. 128) así como también la respuesta de Berent (2006, p. 145). Sobre diversos aspectos del cuerpo de arqueros escitas ver: Plassart (1913); Jacob (1928, p. 64-73); Hall (1989); Lissarrague (1990, p. 125-127); Tuci (2004, 2005); Couvenhes (2012); Pritchard (2018); Ismard (2014, p. 521-523, 2015, p. 74-79). Sobre los Once debemos decir que cumplían con las características de la mayoría de las magistraturas en tanto se trataba de una cargo anual, que se elegía a través de un sorteo entre los ciudadanos y que debían rendir cuentas al final del mandato. Su función consistía en ejecutar a los kakoûrgoi, esto es, ladrones, asaltantes y otros delincuentes que eran sorprendidos in fraganti y confesaban. Generalmente no realizaban arrestos por iniciativa propia, no podían traspasar propiedades de ciudadanos e incluso, podían ser sentenciados a muerte: Hansen (1976, p. 9-25); Christ (1998, p. 528); Berent (1996, p. 41, 2000a, p. 261, 2004, p. 139, 2006, p. 145-146); García (2006, p. 90-96); Reiss (2007, p. 49-50, n. 1). 29 Herman (2006, p. 232) estima - contabilizando solamente 300 arqueros escitas - que había una ratio de un agente capaz de ejercer la coerción cada 781 habitantes. Cf. Berent (2000a, p. 261, 2004, p. 115). ${ }^{30}$ Se puede traer a cuenta al respecto la fuga de Alcibíades relatada por Tucídides (6.61.6-7) y el caso contrario de Sócrates que conscientemente opta por evitar la evasión como vemos en Platón (Cri. 50a).
} 
aceptan ese destino y no se resisten? ¿por qué los miembros de la aristocracia no movilizaron un "ejército privado" a partir de sus riquezas, familiares, amigos, clientes, y relaciones de xenía para hacer frente a tan, aparentemente, endeble aparato coercitivo?31 Al respecto, Finley (1986, p. 40) había evocado la propia legitimidad del sistema democrático a lo que puede sumársele el consenso entre los ciudadanos (homónoia) y las presiones morales que ejercía la comunidad contra aquellos miembros que vulneraban las leyes de la ciudad (Ober, 1989, p. 297-300). Sin embargo, se trata de elementos que, si bien son importantes, también resultan insuficientes (Herman, 2006, p. 233-234), en particular cuando, como ocurrió con cierta frecuencia, las condenas, en particular las que recayeron sobre los políticos atenienses, resultaban ser injustas (Knox, 1985).

Por tanto, junto a las limitadas instituciones específicas dedicadas al control social existían otros mecanismos que ocasionalmente y de modo no permanente estaban a disposición de la pólis para ejercer la coerción y cumplir con las tareas “estatales”. Nos referimos, en primer término, al denominado self-help, self-defense o voluntary prosecution por los autores de lengua inglesa. ${ }^{2}$ Con estos conceptos se definen las acciones a partir de las cuales alguien de forma unilateral y sin que medie la intervención de un tribunal, busca satisfacer un derecho o ejecutar una pena contra la persona o la propiedad de otro individuo. La ausencia de un sistema público de fiscales (Osborne, 1985, p. 7) y de una fuerza policial orientada a asegurar el cumplimiento de los nómoi hizo necesario que exista un alto compromiso por parte de los ciudadanos a la hora de iniciar, conducir y ejecutar las acciones legales ayudados de manera informal por parientes, amigos y vecinos. 33 La oratoria forense constituye un buen reservorio de este tipo de procedimientos. Siguiendo el trabajo reciente de Harris (2013, p. 21-59) - y sin que ello implique aceptar su posicionamiento en relación

\footnotetext{
${ }^{31}$ Dos de los estrategos de la batalla de las Arginusas deciden no volver a Atenas; otros seis son juzgados y condenados a muerte. Cf. Jenofonte (Hell. 1.7.34); Diodoro Sículo (13.101-3).

32 Berent (1996, p. 40, 1998, p. 335, 2000a, p. 261, 2000b, p. 7, 23, 2004, p. 110-111). Cf. Hansen (1976, p. 9-25); Lintott (1982, p. 26-28); Osborne (1985, p. 7); Rihll (1993, p. 86-87); Hunter (1994, p. 149151); Christ (1998, p. 521-531); Riess (2007, 49-57); Harris (2007, 2013, p. 21-59); Lanni (2015).

33 Según Demóstenes (21.223-4), la fuerza (iskhýs) de las leyes, su poder (dýnamis), reside en el apoyo que ellas deben recibir de parte del dêmos para ser todopoderosas (kyríous) y ayudar a quien las necesita. En el mismo sentido se entiende por qué para Aristóteles (Pol. 1269a20-3) la fuerza de la ley (nómos iskhýn) proviene del hábito o la costumbre (éthos) que se establece a través de mucho tiempo (dià khrónou plêthos). Ober (1989, p. 300-301) propone que, en Atenas, las leyes nunca tuvieron un carácter "abstracto". Según Berent (1996, p. 47-49, 1998, p. 358-359, 200ob, p. 13-14), por las mismas razones, las leyes en Platón (Crit. 51e) "ruegan", "persuaden" pero no "comandan". Es por esto que en una situación imaginada por Aristófanes (Eccl. 755 y ss.) aparece como alternativa no cumplir con "la ley que se había votado [katà toùs dedogménous nómous]" sin que esto pareciera traer mayores consecuencias para el infractor (855 y ss.).
} 
a la cuestión del Estado y la pólis - se puede afirmar que, si bien los ciudadanos "privados" podían desarrollar ciertas y limitadas tareas vinculadas a la coerción, 34 se debe reconocer que éstas estaban reguladas por la pólis, o mejor aún, por la comunidad de los politai, que podían tanto intervenir a través de los magistrados como así también juzgar lo actuado con posterioridad. Este tipo de acciones no eran arbitrarias ni el fruto de la mera voluntad o capricho del individuo ya que siempre se realizaban teniendo en cuenta las leyes, las restricciones que estas imponían y las costumbres de la comunidad. 35 También es importante notar que no es cualquier individuo quien puede desarrollar tareas coactivas sino que son fundamentalmente los ciudadanos, es decir, aquellos que forman parte de la comunidad política en tanto politai.

Por otro lado, no era solamente de esa manera que la ciudad democrática aseguraba su orden interno. Es de suponer que cuando, ocasional o excepcionalmente, una amenaza seria al orden establecido aquejaba a la ciudad, era bastante limitado aquello que podría haber hecho un ciudadano aisladamente, aunque, la ley citada por Andócides (1.96-7) habilitaba la práctica del asesinato preventivo contra quienes aspiraran a la tiranía o intentaran desestabilizar el poder del dêmos. ${ }^{36}$ En estos contextos de fuerte tensión social, la ciudad podía llegar, incluso, a movilizar militarmente a los ciudadanos, especialmente a los hoplitas, para actuar no contra un enemigo exterior sino contra algún intento de desestabilizar el orden político de la ciudad. No queda duda de que, los hoplitas del ejército constituían el colectivo que mayor poder de coerción podía concentrar superando a cualquier otro agrupamiento que se le pueda oponer dentro de la pólis (Herman, 2006, p. 240-242).37 El contexto del año 415 constituye un escenario ideal para entender la cuestión ya que frente a una amenaza (o supuesta amenaza) al orden político, los magistrados actúan y convocan al

\footnotetext{
34 Pero a la vez el ciudadano podía recurrir a los tribunales y, como vemos en Demóstenes (21.76), no actuar guiado por la ira (metà tês orgês).

35 Creemos, con Berent (2004, p. 128-129, 2006, p. 157-158) que esto no debe necesariamente indicar estatalidad como parece proponer Hunter (1994, p. 187): "For individual acts of self-regulation were neither arbitrary nor capricious. They must respect certain broad rules laid down by the state". Cf. Reiss (2007, p. 54) para quien desde Dracón en adelante "the subordination of self-help to the judicial process is clear"; Herman (2006, p. 237); Harris (2007, 2013, p. 21-59); Lanni (2015).

${ }^{36}$ Incluso en ese contexto, la acción no era arbitraria ya que quien la ejecutara debía hacerlo públicamente e incluso podía, posteriormente, ser escrutado por los jurados y condenado. Cf. Herman (2006, p. 235-7).

37 Cf. sin embargo lo que creemos que es una distorsión interesada de Viejo Oligarca (1.2). Según el autor del panfleto oligárquico, los pobres (hoi pénetes) y el dêmos que hacen funcionar las naves "rodean a la ciudad de más fuerza que los hoplitas, los nobles y las personas importantes". No cabe duda de que el armamento, entrenamiento, experiencia y versatilidad hacían de los hoplitas una fuerza sin par en la ciudad.
} 
Diego Paiaro. La Pólis, el Estado y los Ciudadanos de la Democracia Ateniense...

ejército para defender a la democracia. ${ }^{8}$ En el mismo sentido se debe destacar que los golpes oligárquicos del 411 y 404 debieron traer hoplitas desde otras ciudades o bien haber desarmado a los atenienses para triunfar. 39 Lo anterior nos muestra que en última instancia y cuando la situación lo ameritaba, los ciudadanos-soldados 40 funcionaban como un colectivo capaz de ejercer una capacidad de coacción que se imponía para garantizar el orden social y político. El hecho de que los atenienses no se encontraran movilizados militarmente de forma constante, no nos debe hacer perder de vista que en ciertas ocasiones cumplían las tareas esenciales de y necesarias para todo Estado. ${ }^{41}$ Sin embargo, no se debe pensar que se trataba de una institución que existía para el ejercicio de la coerción; más bien, se trataba de una comunidad de ciudadanos que se (auto)organizaba para su propia protección y regulación social.

Comunidad Indivisa y Poder Elidido: La Antropología Política en la Atenas Democrática

Ahora bien, en el apartado anterior hemos podido notar cómo las particularidades de la organización de la ciudad democrática, hacen que esta sea un objeto de difícil aprehensión por parte de las clásicas teorías del Estado lo que, finalmente, determinó que los investigadores tiendan a ver frecuentemente en Atenas a un Estado con características peculiares, excepcionales, o un Estado "incompleto" o, directamente, como una sociedad carente de Estado. A la vez, el análisis de esa

\footnotetext{
${ }^{38}$ La pólis habilitó mecanismos para las denuncias, los arrestos y la vigilancia de la ciudad (Thuc. 6.27) y los magistrados convocaron a los generales y el ejército: Andócides (1.45); Tucídides (6.61.2). Cf. Finley (1986, p. 36); Herman (2006, p. 253-254). En relación a la cuestión de la disponibilidad de armas para los ciudadanos atenienses, Herman (1994, 2006, p. 239-240) infiere a partir de Tucídides (1.5.3, 6.3) que podría existir cierta prohibición de llevar armas para la gente común (principalmente aquellas utilizadas para la autodefensa: sídera) aunque es seguro que los hoplitas (entre 18.000 y 25.00o para el 431) disponían en su casa del armamento pesado (tà hópla). Rihll (1993, p. 87) destaca a su vez que las armas en poder de los ciudadanos no eran inferiores en cuanto a tecnología o efectividad a las detentadas por las “organizaciones coercitivas del Estado". Cf. Finley (1986, p. 37).

39 En el mismo sentido habría operado Pisístrato quién, según Aristóteles (Ath. Pol. 15.2-3), luego de obtener dinero y contratar soldados a sueldo (stratiótas misthosámenos) quitó las armas a los ciudadanos (parelómenos toû démou tá hópla). Por su lado, los Treinta (Arist. Ath. Pol. 37.2; Xen. Hell. 2.3.20; Lys. 12.95) actuarían de modo análogo. Se debe recordar que para Aristóteles (Pol. 1311a 11-12) una de las características de la tiranía era desarmar al dêmos. Cf. Berent (1998, p. 338); Herman (2006, p. 242-245) y Loraux (2008, p. 75 y 80) que a la vez destaca el papel de los hoplitas en las restauraciones de la democracia.

${ }^{40}$ Nuestra propuesta difiere en un pequeño matiz de la de Herman (2006, p. 254) para quién "the hoplite army acts as a backup to the routine coercive agency". Creemos que no se debería, en estos casos, pensar al ejército como una "institución" que actúa en un momento de crisis ya que, como plantea Finley (1986, p. 37), estamos frente a ciudadanos que voluntariamente responden al llamado de la ciudad. Lo anterior se relaciona con el hecho de que no se pueda separar claramente participación militar de participación política.

${ }^{41}$ En este sentido, Rihll (1993, p. 86) dirá que se trata de una sociedad "in wich the citizens contitute the strongest coercive force in the state".
} 
organización de la ciudad democrática nos permitió postular la posibilidad de pensar al conjunto de los ciudadanos como una comunidad que se (auto)organizaba como instancia superior - es decir, sin arreglo a un “otro", grupo, clase, institución, etc. por fuera y por encima de ella misma - para garantizar el orden social existente. $4^{2}$ La forma “privada” en la que en algunos contextos aparecía la coerción - que, recordemos, se encontraba regulada, limitada e incluso juzgada por los ciudadanos en tanto comunidad - no debería hacernos perder de vista este elemento que consideramos vital.

Resulta entendible, entonces, el hecho de que, como se ha pensado frecuentemente y hemos tratado en el apartado anterior, el Estado no haya aparecido en el contexto de la pólis como una entidad abstracta que se sobre imponía a la sociedad sino que se encontraba consustanciado con el cuerpo político, con la comunidad de los polîtai atenienses (Ehrenberg, 1960, p. 88; Vernant, 1992, p. 57-58, y n. 10; Anderson, P., 1997, p. 38; Rosenberg, 1994, p. 79; Routledge, 2014, p. 75-76). En la ciudad democrática, como lo ha propuesto Castoriadis (1997, p. 203), no existía el Estado "como instancia separada de la colectividad política" y el poder "es la colectividad misma que lo ejerce". Para evitar los callejones sin salida, conviene pasar de un análisis centrado en la materialidad del Estado, sus monopolios, capacidades, instituciones, elementos, etc. a uno volcado a la indagación de sus funciones, lógicas y prácticas ya que este cuenta, desde nuestro punto de vista, con la ventaja de poder abordar la cuestión desde una perspectiva histórica mucho más dinámica y alejada de las opciones binarias del “con" o "sin” Estado. En este sentido, creemos posible plantear una interpretación de la dinámica de la pólis democrática a partir de una doble lógica.

En primer término, la comunidad cívica se situaba como externa, separada y jerárquicamente diferenciada de quienes no contaban con derechos de ciudadanía. Éstos se encontraban sometidos al control del conjunto de los ciudadanos que, colectivamente, controlaban la capacidad de ejercicio de la coacción a pesar de que ésta haya sido frecuentemente ejercida de forma "privada". Por ejemplo, en relación al caso de los esclavos conviene citar un pasaje de Platón (Rep. 578e):

$4^{2}$ El propio Berent (2000a, p. 264) llega a reconocer que "in a certain sense the citizens did have a monopoly on the application of physical force". 
-...si alguno de los dioses sacara de la pólis [tês póleos] a uno solo de esos hombres que poseen cincuenta esclavos [andrápoda] o más, con su mujer e hijos, y lo pusiese con el resto de su patrimonio y de los sirvientes [tôn oiketôn] en un desierto donde ningún hombre libre [tôn eleuthéron] pudiera acudir en su auxilio [boethéesein], ¿cuál piensas que sería el temor que lo asaltase, y cuán grande, de que él, sus hijos y su mujer perecieran a manos de los esclavos [tôn oiketôn]?

-El más grande, opino.

En este corto fragmento de diálogo aparece claramente sintetizado de qué manera el conjunto de la ciudadanía operaba como protección (y control) del polítes frente a los esclavos en tanto la vigilancia "privada" del amo se encontraba respaldada por el resto de la comunidad. Como afirma Glaucón (578d), "toda la ciudad [pâsa he pólis] va en auxilio [boetheî] de cada uno de estos individuos [tôn idiotôn]". También en Jenofonte (Hier. 4.3) leemos que "los ciudadanos [polîtai] se defienden mutuamente [doruphoroûsi mèn allélous] de los esclavos [epì toùs doúlos] prescindiendo del salario [áneu misthoû]". El hecho de quienes puedan "defenderse mutuamente" o esperar la ayuda "toda la ciudad" sean los ciudadanos no es menor ya que expresa una clara escisión en la sociedad ateniense dejando de un lado a los que ejercen el control (sea privada o colectivamente) y del otro, a quienes lo padecen.43 Es esta situación la que llevó a algunos autores a esgrimir el concepto de citizen-state en tanto la ciudad monopoliza el uso de la fuerza a través de sus ciudadanos frente a los no ciudadanos (Runciman, 1990; $\mathrm{cf}$. Hansen, 1993).44

Pero si, por un lado, resulta claro que la comunidad de los ciudadanos encontraba maneras de garantizar el sometimiento de los excluidos del cuerpo cívico, por otro lado, la pólis no se erigió como un Estado para asegurar el dominio de unos ciudadanos sobre otros. Nuestro postulado consiste en pensar que allí, en las relaciones entre los polîtai, operaba una lógica radicalmente distinta; esto es, una lógica similar a la que describe Clastres (2001, 2008; cf. Campagno, 1998, 2014)45 para las sociedades

\footnotetext{
43 Nuestra interpretación se opone aquí a la de Berent (2004, p. 133, cf. 1998, p. 338, 2000a, p. 264-266, 2004, p. 133-134, 2006, p. 144-145, 154-155) cuando afirma que "in a sense the citizens "ruled» the slaves, their «rule» was applied by non-state mechanism" en tanto no era mediado por un aparato coercitivo. Desde nuestra perspectiva, si hay gobierno de unos sujetos sobre otros, dominadores y dominados, estamos frente a una situación no posible de ser pensada en condiciones no estatales (Clastres, 2001, p. 112, 158, 201).

44 Cf. Morris (1991, p. 48, 2009, p. 136-141); Herman (1987, p. 162-165); Gellner (1991, p. 28, 1994 , p. 23); Berent (2000a, p. 260, 200ob, p. 16-17. 2004, p. 112-113).

45 Hace ya algún tiempo, Loraux (2007, p. 43) había planteado que aquel historiador de la Grecia antigua se sentirá "como si estuviera en tierra conocida" cuando lea al antropólogo francés. A pesar de ello, lo
} 
primitivas, es decir, la de una "sociedad contra el Estado" en donde se aplican constantemente mecanismos para evitar la diferenciación y subordinación, en nuestro caso, de unos ciudadanos por otros. Dicha lógica operaría de forma estrictamente circunscripta al grupo de los ciudadanos ya que pensamos que, en términos generales, la sociedad ateniense no cumplía con las condiciones de lo que para Clastres (2001, p. 111-112, 115, 122, 143, 158, 175-176) eran las "sociedades primitivas" en tanto “sociedades sin Estado" que no poseen "un órgano de poder político separado" ni presentan una división "entre dominadores y dominados" por lo que "son homogéneas en su ser, indivisas”. La existencia de esclavos, metecos y sometidos al imperialismo ateniense - todos ellos carentes de los derechos de ciudadanía que aseguraban la capacidad de acción política - hacen impensable a la demokratía bajo tal modelo. Sin embargo, algunas pautas descriptas por el antropólogo francés para explicar a las “sociedades indivisas" pueden ser de utilidad para aprehender lo que para nosotros es una comunidad indivisa ${ }^{46}$ que carece de dominadores y dominados: nos referimos a la comunidad de los polîtai atenienses, el cuerpo político, los sujetos que disfrutaban de modo igualitario de la ciudadanía.

Para comprender aquello que proponemos llamar comunidad indivisa, resulta fundamental tomar en cuenta la igualdad jurídica y política que se desarrolló entre los ciudadanos durante la democracia. Esta igualdad hizo de los sujetos habilitados para la participación política ciudadanos activos en la administración de la ciudad sin que sus diferencias sociales, económicas o familiares fueran un criterio limitante (Finley, 1986, p. 95-128; Sinclair, 1999). De este modo, se dio una situación particular dado que

cierto es que, hasta muy recientemente - Oliveira Gomes (2007), Paiaro (2011a, 2012a, 2014) e Ismard $(2014,2015)$ - resultaba casi imposible encontrar a Clastres citado por los especialistas de la antigüedad griega. Morris (1991, p. 49) es una muestra y, a la vez, una excepción: si bien reconoce que "to borrow Clastres' phrase, the polis was a case of «society against the state»", el autor no profundizó nunca esta línea interpretativa. Deben destacarse, sin embargo, los intentos de acercar los postulados de Clastres al análisis de la Antigüedad (no solo clásica) reunidos por Campagno (ed. 2014, 2014, p.17-28) recientemente.

${ }^{46}$ Preferimos hablar de "indivisión" y no de "unidad" puesto que consideramos que hay una voluntad activa y una conciencia por parte de esa comunidad en el sentido de rechazar y prevenir su escisión, cf. Clastres (2001, p. 202); Lefort (2007, p. 288-291, 303-7); Loraux (2007, p. 256-257). Con respecto a la idea de "comunidad", para Clastres (2001, p. 199) la "comunidad primitiva" es "más que los grupos que reúne [familias, linajes, clanes etc.], y ese plus la determina como unidad propiamente política. La unidad política de la comunidad encuentra su inscripción espacial inmediata en la unidad de hábitat: la gente que pertenece a la comunidad vive junta en el mismo sitio [...] Esta determinación trasciende la variedad económica de los modos de producción, ya que es indiferente al carácter móvil o fijo del hábitat [...]”. Aquí vemos una analogía respecto de cómo se debería definir la comunidad de los ciudadanos, donde la característica de grupo local está presente en la apropiación del suelo - cf. las reflexiones de Padgug (1981) - pero en su aspecto político trasciende el carácter fijo y por eso resulta un lugar común la idea de que "son los hombres quienes constituyen la ciudad [ándres gàr pólis]", Tucídides (7.77.7); cf. Paiaro (2012a). 
entre los ciudadanos se encontraba ausente la diferenciación jurídica o política que es común, definitoria y fundamental para las sociedades precapitalistas en tanto estas suelen partir de ese tipo de escisiones para estructurarse con sus divisiones clasistas, sus relaciones de dependencia, dominación, coacción y explotación (Wood, 2000, p. 211-76; Plácido 1989, p. 66-76).47 Al no existir puntos de anclaje capaces de articular al interior del cuerpo cívico una escisión entre dominantes y dominados (o entre quienes ejercen la coerción y quienes están sometidos a ella), queda abierta la posibilidad de analizar las relaciones entre ciudadanos valiéndose de las herramientas analíticas brindadas por la antropología política para aprehender el funcionamiento de las sociedades llamadas "primitivas”. En función de esto, analizaremos a la luz de la jefatura "salvaje", determinados aspectos del liderazgo político en la democracia ateniense junto con los diferentes mecanismos que la demokratía puso en práctica para evitar la concentración del poder político, es decir, para continuar siendo una comunidad indivisa.

A pesar de haberse basado en la participación activa y directa de los ciudadanos en diferentes instituciones colectivas como el Consejo y los jurados pero fundamentalmente en la Asamblea, 48 un aspecto insoslayable del funcionamiento democrático en la Atenas clásica fue la existencia de diferentes "líderes políticos" o demagogos 49 que, en su gran mayoría, procedían de las familias tradicionales de la aristocracia. $5^{\circ}$ Coexistiendo con el activismo político popular, los líderes cumplían un

\footnotetext{
47 En Paiaro (2011b), analizamos en extenso cómo se constituye la excepcionalidad ateniense en torno a la cuestión de la coacción extraeconómica a partir de las reformas de Solón en el s. VI. Para nuestro análisis de la problemática centrado en la cuestión de la dependencia, la explotación y la dominación, ver Paiaro (2012b).

48 En términos generales, véase la propuesta de Starr (1990, p. 13-31). Cf. Sinclair (1999, p. 44-47), Finley (1986, p. 135-136) y Gallego (2003, p. 95-128). La Asamblea incluso operará, en última instancia, como la manifestación concreta de la pólis a tal punto que, frecuentemente, el término dêmos - que entre otros significados designaba a los ciudadanos - es asimilado directamente a la Asamblea. Cf. Hansen (1983, p. 139-158, 1989, p. 213-218, 1991, p. 124-160); Lonis (1983, p. 105, n. 83); Ruzé (2003, p. 37-53, esp. 50-51); Plácido (1997, p. 215).

49 El líder político es referido en las fuentes antiguas a partir de diversos vocablos: politeuómenos, politikós, prostátes toû démou, rhétor, demagogós etc. Véase Sinclair (1999, p. 239, n. 4); Connor (1992, p. 99-119); Hansen (1989b, p. 1-24); Ober (1989, p. 105-108). Si bien cada término tiene su propia especificidad y ninguno puede ser traducido sin problemas a la idea contemporánea de "político", en adelante utilizaremos indistintamente algunos de ellos o sus traducciones más cercanas para referirnos a quienes, de entre los ciudadanos, se destacaban por su participación en las magistraturas, los tribunales, la Asamblea, es decir, en la vida política ateniense. Cf. Hansen (1987, p. 49-54). Con respecto a "demagogo", lo utilizaremos de forma neutral sin tomar en cuenta su frecuente carga negativa. Cf. Finley (1981, p. 31-32).

5o Al menos hasta la muerte de Pericles y la aparición en la escena de lo que Connor (1992) llamó "los nuevos políticos", que procedían de sectores sociales más modestos en lo económico y menos prestigiosos en cuanto a lo familiar. Cf. Finley (1981, p. 28), Aristóteles (Ath. Pol. 28.1) y Rhodes (1981, p. 344-351). Algunas de las características de los "nuevos líderes" aparecen enunciadas en las fuentes: Aristófanes (Eq. 180-222); Eúpolis (117 CAF) y Aristóteles (Ath. Pol. 28.3-4). Para Ober (1989, p. 84-
} 
papel de primer orden - que para Finley (1981, p. 31-32) era "estructural" del sistema político (cf. Sinclair 1999, p. 76) - aunque no ocupaban un lugar formal en el entramado institucional de la pólis. Pero, si el liderazgo político no se basaba en tener una posición en la estructura del Estado o en cumplir una función estatal, ¿cuál era la fuente de poder de los líderes?, o, mejor aún, ¿̇se podría decir que, verdaderamente, tenían tal poder? Es aquí donde la antropología política de Clastres puede ayudar a iluminar la situación.

En su análisis de la jefatura indígena, Clastres (2001, p. 112-114, 116, 123, 127128, 144, 2008, p. 11, 26-28, 33, 41, 175-176) habla de "esa exótica particularidad de las sociedades primitivas” en las que "aquellos que llamamos líderes están desprovistos de todo poder" puesto que "no dispone(n) de ninguna autoridad, de ningún poder de coerción, de ningún medio de dar una orden", en tanto allí "lo político se determina como campo fuera de toda coerción y de toda violencia, fuera de toda subordinación jerárquica, donde, en una palabra, no se da ninguna relación de orden-obediencia”. En virtud de ello, el líder “nunca está seguro de que sus órdenes serán ejecutadas” y "su poder depende de la buena voluntad del grupo”, voluntad a la que, por otro lado, debe someterse si desea continuar en ese lugar y no ser descartado. En síntesis, "el jefe no manda porque no puede más que cualquier miembro de la comunidad" y "no puede imponerla [su intención] por ningún medio a la sociedad puesto que [...] está desprovisto de poder". A su vez, el líder indígena "debe ser generoso con sus bienes" y "sólo un buen orador puede acceder al liderazgo" en tanto "el talento oratorio es una condición y también un medio del poder político”. Si bien tal condición implica que el jefe será escuchado con más interés en virtud de su prestigio, ello no conlleva en modo alguno "poder" ya que "la palabra del jefe" no puede nunca transformarse en "palabra de mando, en discurso de poder”. Por último, si el deseo de poder del jefe se hace evidente, operan mecanismos para neutralizarlo: "se lo abandona, a veces, incluso se lo mata" (cf. Gledhill, 200o, p. 31-5, 54-8).

Si pensamos a través de estos postulados en la figura del líder político de la demokratía podremos ver situaciones y prácticas que funcionan bajo la misma lógica. $5^{1}$ Así, se puede afirmar que los demagogos estaban, en buena medida, “desprovistos de

103), la élite ateniense se adapta a la democracia y encuentra en el liderazgo de las masas un lugar para continuar participando políticamente.

${ }^{51}$ Toda comparación tiene sus límites y nunca las situaciones son totalmente análogas. Al respecto, Loraux (2008, p. 201-217) ha hecho un elogio del anacronismo y defendido su uso controlado. Cf. la propuesta de Detienne (2001, 2007). 
todo poder", si entendemos tal "poder" en un sentido restringido, 52 es decir, como la capacidad de coaccionar o ejercer la violencia para imponer un mandato y obtener obediencia. Al igual que su par salvaje, el líder político ateniense no disponía de ningún "medio de dar una orden" y se encontraba incapacitado de imponer mecánicamente su voluntad al resto ya que no contaba con ningún derecho que lo ponga por encima de los ciudadanos comunes (Ober 1989, p. 108; cf. Gil Fernández 2009, p. 77) ni disponía de aparato de coerción alguno para forzar la obediencia del dêmos (Berent, 2000a, p. 262, 200ob, p. 8, 2004, p. 111. Cf. Finley, 1979, p. 34-35; Rhodes, 2000, p. 467). Si bien resultó frecuente que los líderes más reconocidos ocupen diferentes magistraturas especialmente las militares -, su actividad política no se desarrollaba principalmente desde allí, como parte de una función “administrativa” sino, más bien, encontraba su lugar en los debates que se daban en las instituciones colectivas de la ciudad, especialmente, en la Asamblea (Rhodes, 1995, p.157). Pero incluso si era seleccionado magistrado - una de las características de la democracia es que la mayoría de las magistraturas eran elegidas por sorteo -53 la capacidad de mandar del líder democrático era muy limitada (tenían “very little power”, Rhodes, 1995, p. 154).

$\mathrm{Al}$ respecto, Finley (1986a, p. 34-35) ha hecho una interesante comparación: frente al imperium del que disponían algunos magistrados en la República romana y que los habilitaba a ejercer la coercitio contra los ciudadanos, sus pares atenienses apenas podían "multar a un tendero delincuente” pero, de ningún modo, ejercer la coerción sobre otro polítes (cf. Allen 2000, p. 40-45; Herman 2006, p. 229-246, esp. 238). A la vez, las características que tenían las magistraturas contribuían a delimitar el margen de acción de los magistrados: se trataba de cargos (generalmente) colegiados, de duración acotada (principalmente anual), en los que frecuentemente estaba prohibido desempeñar un segundo período, y que, finalmente, se encontraban sometidos a diferentes escrutinios de tipo judicial (Ober 1989, p. 7).54 Es por ello que se puede hablar de un "poder ejecutivo elidido" en tanto los magistrados no se

\footnotetext{
$5^{2}$ La tradición occidental habría pensado el poder en sentido restringido en tanto inseparable de "su predicado, la violencia”, pero el poder puede tener un carácter no coercitivo según la perspectiva de Clastres (2008, p. 19-20).

53 En Heródoto (3.80.6) el sorteo aparece como uno de los principios de la democracia para evitar el poder excesivo. Cf. Aristóteles (Pol. 1273b40-41, 1274a5, 1294b7-9 y 1317b28-30); Hansen (1991, p. 235237); Sancho Rocher (1997, p. 184-185). Véase en los Dissoi Logoi (7) los argumentos aristocráticos contra la práctica. Cf. Solana Dueso (1996, p. 166-171).

54 Para Sinclair (1999, p. 237-238) tales características hacían de unos magistrados tan importantes como los arcontes, sujetos despojados de "cualquier auténtico poder en términos de influencia política". Para los aspectos más relevantes de las magistraturas, véase Hansen (1991, p. 225-245). Cf. Gil Fernández (2009, p. 70-71).
} 
diferenciarían en mucho del resto de los ciudadanos (Osborne 1985, p. 9; cf. Berent 1996, p. 42-43, 1998, p. 342, 2000a, p. 260, 2000b, p. 8, 2004, p. 111). Esto era hasta tal punto así que incluso los comandantes del ejército - una de las pocas magistraturas electivas a través del voto y en las que no existían límites para la reelección (Plut. Per. 16.3; cf. Piérart, 1974) - tenían "un poder constitucional muy pequeño" (Rhodes 2000, p. 466). Si bien durante las campañas militares los generales podían tomar algunas decisiones por su cuenta sin necesidad de consultar a la Asamblea - y recordemos que también el jefe indígena tenía un poder "hasta absoluto a veces" en tiempos de guerra (Clastres, 2008, p. 27, cf. 177) -, constituye un dato no menor que luego se debían refrendar dichas decisiones frente al resto del dêmos reunido en Asamblea o en los tribunales, pudiendo los responsables sufrir alguna condena. 55

Ahora bien, esa no diferenciación jurídica y política de los líderes y este carácter limitado del poder de los magistrados determinaba que el principal locus de actuación política haya sido la Asamblea y, en menor medida, los tribunales y el Consejo. Esto se daba en un contexto de plena vigencia de la isegoría, es decir, del reparto igualitario - entre los ciudadanos - de la "palabra política", de la capacidad de hablar y hacer propuestas en la ekklesía. ${ }^{6}$ En virtud de ello - como sucede con el bigman de Sahlins (1972, p. 40-41) - el político en Atenas dependía de su carisma personal y de su capacidad oratoria de convencer a los polittai si quería ver sus pretensiones realizadas. En primer lugar, entonces, se debe decir que en Atenas un político es, fundamental y principalmente, un buen orador. Es la persuasión, la capacidad argumentativa, el modo de desenvolverse en la arena pública - especialmente en la Asamblea - lo que constituye la principal herramienta con la que cuenta un demagogo. La habilidad oratoria resultaba central en una "sociedad cara a cara" 57 en donde la

55 Tucídides (4.65) relata cómo en el año 424 los generales atenienses pactaron un tratado en Sicilia pero al regresar a Atenas el dêmos condenó a dos de ellos al destierro mientras que a otro le impuso una multa. El propio Tucídides (5.26) fue desterrado por su actuación en Anfípolis. Cf. Knox (1985, p. 135, 146). De modo análogo, los jefes tupinambas tenían una autoridad "indiscutida durante las expediciones guerreras" que, por otro lado, "se encontraba sometida al control del consejo de ancianos en tiempos de paz" (Clastres, 2008, p. 27; cf. 2001, p. 113, 2008, p. 177).

$5^{6} \mathrm{El}$ término isegoría constituye un virtual sinónimo de demokratía y debe referirse conjuntamente aunque no confundirse - con el de parrhesía, la libertad de "decir cualquier cosa" o el "hablar francamente". Cf. Heródoto (5.78); Nakategawa (1988); Hansen (1991, p. 81-85); Griffith (1967, p. 115126); Lewis (1971, p. 129-140); Raaflaub (2004, p. 96, 222-223); Ober (1989, p. 78-79, 108); Loraux (1993, p. 182-183).

57 Finley (1979, p. 25-26, 1986, p. 109) retoma el concepto de Laslett (1956). Osborne (1985, p. 65) criticó tal caracterización para la pólis aunque la consideró válida para el demo. Cf. Hansen (1991, p. 60); Cohen (2000, p. 104-129) y Anderson, G. (2003, p. 2-5). 
Diego Paiaro. La Pólis, el Estado y los Ciudadanos de la Democracia Ateniense...

política encuentra su lugar en los espacios públicos de debate oral;58 es por eso que un líder (anèr demagogòs) como Cleón es descrito por Tucídides (4.21.3) como "el más persuasivo para la multitud" (tó pléthei pithanótatos).59

Pero, junto con la pericia retórica, son la generosidad y el prestigio que ella conlleva - o la "explotación del rico por la comunidad" como llama Clastres a las obligaciones económicas que el líder tiene con la colectividad - los rasgos que definen al jefe en las sociedades estudiadas por el antropólogo francés (2001, p. 111-116, 144148, 202, 2008, p. 27-37, 175-176) y, en parte, al líder de la demokratía. En Atenas existían mecanismos tanto voluntarios (evergetismo) como obligatorios (liturgias) para el desarrollo de la "generosidad" de los ciudadanos "ricos" con la multitud (cf. Rhodes 1982; Plácido 2006). Si bien no podríamos afirmar sin temor a equivocarnos que dicha "generosidad" constituye una "servidumbre" como entre los jefes indígenas (Clastres 2001, p. 202, 2008, p. 28), es cierto que las cargas económicas que el dêmos le impone a la elite - o que algunos de sus miembros se autoimponen - eran percibidas como un sometimiento por el pensamiento oligárquico. Así, para el Viejo Oligarca (1.13), mientras que "el pueblo" (ho dêmos) se enriquece, con las coregías, gimnasiarquías y trierarquías, "los ricos" (hoi ploúsioi) se vuelven pobres (penésteroi gígnontai). (Tamiolaki, 2013) Pero ello no nos debería hacer perder de vista el carácter agonístico, competitivo y propio de la cultura aristocrática que esta forma de usar la riqueza tenía para los sectores ricos de la ciudadanía en tanto mecanismo para la obtención de estima social.

Así, las contribuciones económicas de los ploúsioi ${ }^{60}$ repercutían positivamente en el "prestigio" y la consideración que la comunidad tenía con aquellas personas que,

${ }_{58}$ Finley (1981, p. 29) dirá que "por definición querer dirigir a Atenas implica la carga de intentar persuadir a Atenas y una parte esencial de ese esfuerzo está en la oratoria". Para ello resultaba necesario que los miembros de la elite que quisieran ejercer el liderazgo tuvieran un determinado tipo de instrucción: Ober (1989, p. 156-191); cf. Kennedy (1963, p. 125-133, 154-157, 203-204). En el mismo sentido, Rhodes (2000, p. 467). Mientras, para Clastres (2008, p. 28), "el talento oratorio es una condición y también un medio del poder político” entre los líderes primitivos.

59 Una buena síntesis sobre la importancia de las capacidades oratorias en un sistema político que privilegia la toma de decisiones en contextos de audiencias masivas se puede ver en Ober (1989, p. 104155); cf. Finley (1979, p. 34-35). Resulta de interés la observación hecha por Rihll (1993, p. 86-88) quien, basándose en la distinción de Weber (1964, p. 938-1046) entre sociedades en las que el ejército se arma a sí mismo y sociedades en las que es el Estado el que lo hace, plantea que en las sociedades políadas prevalece la persuasión mientras que en las segundas (orientales) el poder despótico. Para Gil Fernández (2009, p. 74-76) la creencia popular en las virtudes mágicas de la persuasión (peithó) se encontraba detrás de la "irresponsabilidad del dêmos" ya que siempre que el pueblo tomaba una decisión que, con el tiempo, se mostraba errada, la responsabilidad caía sobre el orador que había hecho la propuesta en la Asamblea.

60 Algunos aspectos económicos del liderazgo primitivo merecen ser tenidos en cuenta. Leyendo la obra de Sahlins, Clastres (2001, p. 145) afirma que el big-man "como no puede explotar a los otros para producir un excedente se explota sí mismo, a sus mujeres y a sus parientes: autoexplotación del big- 
de ese modo, solventaban una serie de diversas necesidades que tenía la ciudad. ${ }^{61}$ Es innegable que quienes utilizaban una parte de su fortuna en la ciudad - o en el desarrollo de relaciones de patronazgo con sectores pobres del dêmos (Requena, 2013) -62 aparecían como "benefactores" de la comunidad y que el "prestigio" que a partir de ello se construía podía influir en su capacidad de acción política. ${ }^{63}$ A pesar de ello, de ningún modo se puede decir que la posesión de ese "prestigio" implicaba o devenía en “poder” (cf. Clastres 2001, p. 114, 147). Así, más allá de la citada habilidad para la argumentación oratoria, el rhétor no podía contar con que su palabra - y su política triunfe siempre. Ello implicaba que, por más que el lógos del líder se haya encontrado cargado de cierto "prestigio" que le transmite su enunciante, este nunca se transformaba - como propone Clastres (2001, p. 114) para el jefe salvaje - en "palabra de mando, en discurso de poder” ya que “el punto de vista del líder sólo será escuchado cuando exprese el punto de vista de la sociedad como totalidad" (aunque pensando en Atenas deberíamos reemplazar a "la sociedad" por "la comunidad de los ciudadanos"). 64

Pero, si por un lado, todos estos elementos contribuían a elidir el "poder" de los líderes y magistrados en la Atenas clásica, por otro lado, la demokratía contaba con toda una serie de mecanismos que buscaban operar activamente para evitar el poder pueda ser apropiado, acumulado, concentrado. Estos mecanismos se orientaban a la

\footnotetext{
man y no explotación de la sociedad por el big-man que, evidentemente, no dispone del poder de obligar a los otros a trabajar para él”. Aquí el caso de líder político ateniense es diferente; si bien es cierto que se encuentra incapacitado de explotar a los miembros del cuerpo cívico, sí lo puede hacer con quienes están excluidos de él, especialmente los esclavos, sin que sea necesario el proceder a su autoexplotación o la de sus mujeres y parientes. Sobre la cuestión de la explotación y la imposibilidad de explotar a los ciudadanos, véase Paiaro (2012b).

${ }^{61}$ Rhodes (2000, p. 469-470) sitúa a las liturgias como uno de los mecanismos informales para sustentar las carreras políticas de los miembros de la élite y destaca su carácter competitivo. Clastres (2001, p. 147) afirma que "la sociedad «ofrece» el prestigio, el jefe lo obtiene a cambio de bienes". Estos mecanismos cumplían también la función de evitar acumulaciones de riquezas consideradas peligrosas para el sistema democrático. Cf. Finley (1986, p. 183-6); Ober (1989, p. 30-31, 199-202).

62 Véase las posturas clásicas de Finley (1986, p. 66-8) y Millett (1989). En Gallego (2008, 2009) y Plácido y Fornis (2011) se pueden encontrar las discusiones historiográficas actualizadas.

${ }_{63}$ Los beneficios del uso de la riqueza (pública y privada) para sustentar el liderazgo político son tratados, de un modo grotesco, en Los Caballeros de Aristófanes. Paflagonio, caricatura de demagogo que representaría a Cleón, se jacta de poder reírse del dêmos cuando le plazca y tener siempre su obediencia ya que sabe "qué bocadillos hay que darle" (710-723). Luego (773-776) afirma que cuando fue consejero, "te asigné [al pueblo] en el erario público dinero de a montones, presionando a unos, agobiando a otros, reclamando a los de más allá [...] con tal de serte grato" e inicia una disputa con el Morcillero en donde en diversos pasajes se ofrecen regalos y adulaciones al dêmos para obtener su favor (747-1263).

64 Como ha propuesto Rhodes (2000, p. 474), inclusive las más importantes figuras políticas de Atenas, "they could not be sure of getting the decision they wanted every time". Cf. Finley (1979, p. 34) y Herman (2006, p. 221). En línea con el planteo que venimos sosteniendo, para Berent (1996, p. 57) el objetivo del liderazgo político no sería imponer un orden sino, más bien, coordinar una acción común.
} 
vigilancia de los magistrados, de los líderes políticos y de los sectores ricos de la ciudadanía (Finley 1979, p. 34-38). Más arriba hemos citado que, según Clastres, si el "deseo de poder" del jefe se tornaba evidente para la comunidad, la sociedad tendía a neutralizarlo a través del abandono o, incluso, del asesinato. En este sentido, creemos que en la democracia ateniense funcionó una lógica propia de la "sociedad contra el Estado" en tanto existieron mecanismos que conscientemente operaban para evitar la división entre gobernantes y gobernados, es decir, para impedir la escisión de aquello que hemos definido como comunidad indivisa. ${ }^{65}$ En síntesis, el poder se utilizaba para neutralizarse en tanto era la comunidad la que ejercía el poder sobre los líderes y no viceversa (Clastres, 2001, p. 159; cf. Vernant, 2008, p. 135-138, 143). ${ }^{66}$ Por esto, para Finley (1981, p. 26), “tensión” es la palabra que mejor define a la situación del político en la democracia (cf. Finley 1979, p. 27).

Existieron, entonces, una pluralidad de dispositivos que buscaban mantener la isonomía, la igualdad política, evitando, de ese modo, la concentración del poder en un ciudadano o en un grupo reducido de ellos. ${ }^{67} \mathrm{Si}$ bien no podemos tratar aquí el tema de modo extenso, creemos que enunciar alguno de estos mecanismos es suficiente para explicitar la lógica común con la que operan. En cuanto a los magistrados (y toda aquella persona que cumpla una función pública), se debe decir que estaban sometidos a una inspección previa a asumir (dokimasía) y a la rendición de cuentas al final de su mandato (euthýna) (Roberts, 1982; cf. Hansen, 1991, p. 222-224; MacDowell 1978, p. 170-172) y podían sufrir multas, confiscaciones de propiedad, pérdida de los derechos de ciudadanía (atimía), exilio, ejecución y otro tipo de penas. ${ }^{68} \mathrm{~A}$ su vez, especial mención merece el ostracismo en tanto arma en manos del dêmos especialmente creada para custodiar la isonomía y evitar el surgimiento de potenciales tiranos en las figuras de sujetos que concentrasen un poder considerado excesivo en la arena política. No es un dato aleatorio el hecho de que el ostracismo se desarrolle acompañando a la

\footnotetext{
$65 \mathrm{Al}$ respecto, Picazo (2013) destaca que el igualitarismo no es solamente ausencia de desigualdad sino que es necesaria la existencia de mecanismos que eviten la aparición de las diferencias. Para Berent (2000a, p. 258) se trata de un tipo de sociedad que "resiste la coerción" del poder político.

${ }^{66}$ Es por eso que para un pensador oligárquico (Old Oligarch 1.8), "el pueblo no quiere ser esclavo, aunque la pólis sea bien gobernada, sino ser libre y mandar [eleútheros eînai kaì árkhein]".

${ }_{67}$ Para Picazo (2013) estos mecanismos serían formas residuales de algún período en el que existieron formas de igualitarismo social o político. Acordamos plenamente con Finley (1981, p. 33) cuando afirma que "el ostracismo, el llamado graphé paranómon y el escrutinio formal popular de los arcontes, generales y otros oficiales fueron introducidos deliberadamente como dispositivos de seguridad, contra el poder excesivo de un individuo (potencial tiranía)". Cf. Musti (2000, p. 16-17).

68 Sobre "los riesgos de la jefatura", ver Sinclair (1999, p. 237-280, 291-301). Cf. Finley (1981, p. 33); Rhodes (1995, p. 157-158). Gil Fernández (2009, p. 88-89, n. 28) demuestra que las penalizaciones solían recaer más sobre los magistrados que sobre los demagogos.
} 
democracia en sus sucesivas etapas de nacimiento, auge y declive durante el siglo $\mathrm{V}$ (Paiaro, 2012c). Pero estos mecanismos de control no necesariamente consistían en procedimientos institucionalizados ya que existían otros, externos a la politeía, que ayudaban al control sobre los líderes, como el caso de los "rumores públicos" (Larran 2011; cf. Hunter 1994, 102-116), de la "justicia popular" (Forsdyke 2012, p. 144-170), de la construcción de la figura del héroe trágico en las representaciones teatrales ${ }^{69}$ y el de los llamados "sicofantas", estos últimos, interpretados por Osborne (1990) como un activo dispositivo democrático de regulación política (cf. las reservas de Harvey, 1990). Por último, y sin ánimo de ser exhaustivos, creemos que una pequeña muestra puede resultar ilustrativa de la importancia de este tipo de mecanismos: a lo largo del siglo V fueron multados, ostrastizados, exiliados o ejecutados, entre otros, líderes tan importantes como Milcíades, Arístides, Temístocles, Cimón, Tucídides (hijo de Milesias), Pericles, Sófocles, Tucídides (hijo de Oloros), Cleón, Nicias, Demóstenes, Hipérbolo, Alcibíades, Pisandro y Terámenes (Knox, 1985; cf. Herman, 2006, p. 226; Sinclair, 1999, p. 293-295).

En síntesis diríamos que los atenienses, "supieron inventar un medio para neutralizar la virulencia de la autoridad política” generando una dinámica de poder que se anulaba a sí misma "prohibiendo la emergencia de un poder político individual, central y separado" (Clastres, 2008, p. 40, 180). De este modo, que proponemos llamar comunidad indivisa, el cuerpo cívico durante la democracia ateniense, funcionó a partir de una lógica que intentaba, en última instancia, "el no ser gobernado preferentemente por nadie" (Arist. Pol. 1317b10-5; cf. 1291b30).70

\section{Reflexiones Finales}

A lo largo del trabajo hemos intentado abordar múltiples dimensiones de los debates recientes acerca de la relación entre la pólis y el Estado. A partir de las dificultades con las que se han topado los investigadores para tratar a la democracia de Atenas como una sociedad “con" o "sin" Estado, intentamos demostrar que la

69 En la tragedia, la figura del tirano funciona como un espejo del oligarca de finales del siglo $\mathrm{V}$ y contrasta con el ideal de ciudadano democrático. Cf. Sancho Rocher (2009, p. 33-34) y Gallego e Iriarte (2009, p. 106-118).

70 Recientemente, Ismard $(2014,2015)$ ha desarrollado de forma sólida una argumentación que encuentra varios puntos de contacto con lo que venimos planteando. Partiendo del análisis de los denominados "esclavos públicos" (demósioi) y su función omnipresente en la "administración pública", el autor interpreta eso como un modo de - en los términos de Clastres - resistencia de la pólis frente al Estado como autoridad separada. Al confiar las tareas administrativas (y represivas) a sujetos desclasados, la pólis expulsaba de la vida política el saber y el servicio para, de ese modo, mejor cumplir con la ideología democrática. 
problemática amerita ser abordada de un modo más complejo que la simple aplicación de conceptos y comprobación de presencia/ausencia de determinados elementos considerados fundamentales (monopolio de la coerción, territorio, abstracción, permanencia etc.). En reemplazo, nuestra propuesta se orientó a plantear una explicación de cómo Atenas funcionaba a partir de una doble lógica que garantizaba, por un lado, la dominación y explotación de los excluidos del cuerpo cívico y, por otro lado, la constitución de una trama política que evitaba el desarrollo de relaciones jerárquicas y coercitivas entre los ciudadanos. De esta manera, estimamos, se pueden evitar las perspectivas instrumentalistas del Estado como la presente en de Ste. Croix (1988, p. 337; cf. Berent, 1998, p. 334-335) para quien "el control del estado constituía uno de los premios, de hecho el más grande, de la lucha de clases en el plano político". En efecto, la lucha política no tenía como resultado el control del Estado o la apropiación de los medios de coerción (en tanto objetos, cosas) sino, en contraste, el fin último de las disputas en el plano político estaba orientado a la posibilidad de definir o redefinir el cuerpo cívico; esto es, el establecimiento de las relaciones de pertenencia/exclusión de aquello que hemos definido como una comunidad indivisa. En síntesis, diríamos que la pólis se desenvolvía de forma dinámica a través de una tensión ${ }^{71}$ nunca del todo resuelta entre, por un lado, las prácticas estatales que garantizaban la exclusión/dominación/subordinación y, por otro lado, las prácticas contra-estatales que las evitaban.

Artigo recebido em 11.05.2018, aprovado em 29.06.2018.

\footnotetext{
${ }^{71}$ En sentido similar a lo que hemos argumentado pero tomando como elemento central el papel de los esclavos públicos en la democracia ateniense, Ismard (2014, p. 532; cf. 2015, p. 176-177) ha concluído, recientemente: "Understood from a more flexible perspective, the dynamic that the polis maintained with the statal form instead results from a tension that, by the very nature of Greek political thought, had to remain unresolved. It is true that the polis was a community of citizens exercising their sovereignty through political institutions over a clearly specified territory. Of course, power occupied a prominent place in the city and, in this minimalistic - even derisory - sense, the city was a state. And there was indeed a form of power to which all members of society could relate, even if this political stage was not set apart from the community in order to transcend it. But it is no less true that the existence of a state as an administrative center - or separate authority - was problematic for a civic community that planned to uphold all forms of power in the constitution of its own communal life. In this respect, the development of public slavery at the beginning of the Classical period can be parsed as a mark of «resistance» on the part of civic society to the emergence of a state apparatus - or, in Clastres's words, a type of «coding» through which society intended to preserve its own indivision. [...] By making the people who were in charge of running it invisible, the city prevented the rise of a state that could establish itself as an autonomous authority and, if the situation arose, turn against it”.
} 


\section{REFERÊNCIAS BIBLIOGRÁFICAS}

\section{Fontes Primárias}

Adams, Charles (ed.) Aeschines. Speeches. Cambridge: Harvard University Press, 1919. Burnet, John (ed.) Plato. Platonis Opera. Oxford: Oxford University Press, 1967-1968, 5 vols.

Butcher, S.; Rennie, W. (eds) Demosthenes. Demosthenis Orationes. Oxford: Clarendon Press, 1906-1931, 3 vols.

Godley, Alfred (ed.) Herodotus. The Persian Wars. Cambridge: Harvard University Press, 1920-1925, 4 vols.

Hall, Frederick; Geldart, William (eds) Aristophanes. Comoediae. Oxford: Clarendon Press, 1906-1907, 2 vols.

Kenyon, Frederick (ed.) Aristotelis Atheniensium Respublica. Oxford: Clarendon Press, 1920.

Kock, Theodor (ed.) Comicorum Atticorum Fragmenta. Leipzig: Teubner, 1880-1888, 2 vols.

Lamb, Walter (ed.) Lysias. Cambridge: Harvard University Press, 1930.

Lobel, Edgar; Page, Denys (eds) Poetarum Lesbiorum Fragmenta. Oxford: Clarendon Press, 1955.

Maidment, Kenneth (ed.) Minor Attic Orators in Two Volumes. I: Antiphon, Andocides. Cambridge: Harvard University Press, 1968.

Marchant, Edgar (ed.) Xenophon. Xenophontis Opera Omnia. Tomus I: Historia Graeca. Oxford: Clarendon Press, 1900.

Xenophon. Xenophontis Opera Omnia. Tomus V: Opuscula. Oxford: Clarendon Press, 1920.

Oldfather, Charles (ed.) Diodorus Siculus. Library of History. Cambridge: Harvard University Press, 1933-1967, 12 vols.

Perrin, Bernadotte (ed.) Plutarch. Plutarch's Lives. Volume III. London: William Heinemann, 1916.

Ross, David (ed.) Aristotelis Politica. Oxford: Clarendon Press, 1957.

Storr, Francis (ed.) Sophocles. Vol 1: Oedipus the King. Oedipus at Colonus. Antigone. London: William Heinemann, 1912.

Stuart-Jones, Henricus; Powell, Johannes (eds) Thucydidis Historiae. Oxford: Clarendon Press, 1942, 2 vols.

Weir Smyth, Hebert (ed.) Aeschylus. Cambridge: Harvard University Press, 1926, 2 vols.

\section{Bibliografía Crítica}

Agamben, Giorgio. Estado de Excepción: Homo Sacer, II, I. Traducción de Flavia Costa e Ivana Costa. $1^{\text {a }}$ edición 2003. Buenos Aires: Adriana Hidalgo Editora, 2005. 
Allen, Danielle. The World of Prometheus: The Politics of Punishing in Democratic Athens. Princeton: Princeton University Press, 2000.

Anderson, Greg. The Athenian Experiment: Building an Imagined Political Community in Ancient Attica, 508-49O BC. Ann Arbor: University of Michigan Press, 2003.

2009, p. 1-22.

The personality of the Greek State. The Journal of Hellenic Studies, 129,

Anderson, Perry. Transiciones de la Antigüedad al Feudalismo. Traducción de Santos Julia. $1^{a}$ edición 1974. México: Siglo Veintiuno Editores, 1997.

Berent, Moshe. Hobbes and the «Greek tongues». History of Political Thought, 17, 1, 1996, p. 36-59.

. Stasis, or the Greek invention of politics. History of Political Thought, 19, 3, 1998, p. 331-62.

. Anthropology and the Classics: War, violence and the stateless polis. The Classical Quarterly, 50, 1, 2000a, p. 257-89.

. Sovereignty: Ancient and modern. Polis. The Journal of the Society for Greek Political Thought, 17, 1-2, 200ob, p. 2-34.

. In search of the Greek state: A rejoinder to M.H. Hansen. Polis. The Journal of the Society for Greek Political Thought, 21, 1-2, 2004, p. 107-146.

p. 141-163.

. The stateless polis: A reply to critics. Social Evolution \& History, 5, 1, 2006,

Bobbio, Norberto. Estado, Gobierno y Sociedad. Por Una Teoría General de la Política. Traducción de José F. Fernández. $1^{\mathrm{a}}$ edición 1985. México: Fondo de Cultura Económica, 1989.

Buis, Emiliano. La Súplica de Eris: Derecho Internacional, Discurso Normativo y Restricciones de la Guerra en la Antigua Grecia. Buenos Aires: EUDEBA, 2015.

Burke, Peter. City-states. In: Hall, John A. (ed.) States in History. Oxford: Blackwell, 1986, p. 137-153.

Campagno, Marcelo. Pierre Clastres y el surgimiento del Estado: Veinte años después. Boletín de Antropología Americana, 33, 1998, p. 101-113.

. Introducción: Pierre Clastres, las sociedades contra el Estado y el mundo antiguo. In: Campagno, Marcelo (ed.) Pierre Clastres y las Sociedades Antiguas. Buenos Aires: Miño y Dávila Editores, 2014, p. 7-34.

Editores, 2014.

(ed.). Pierre Clastres y las Sociedades Antiguas. Buenos Aires: Miño y Dávila

Campagno, Marcelo; Lewkowicz, Ignacio. La Historia Sin Objeto y Derivas Posteriores. Buenos Aires: Tinta Limón, 2007.

Canfora, Luciano. El ciudadano. In: Vernant, Jean-Pierre (dir.) El Hombre Griego. Traducción de José A. Ochoa Anadón. $1^{\text {a }}$ edición 1991. Madrid: Alianza Editorial, 1993, p. 139-173.

Cartledge, Paul. Laying down polis law. The Classical Review, 49, 2, 1999, p. 462-469. 
Greek political thought: The historical context. In: Rowe, Christopher; Schofield, Malcolm (eds.) The Cambridge History of Greek and Roman Political Thought. Cambridge: Cambridge University Press, 2005, p. 11-22.

University Press, 2009.

Ancient Greek Political Thought in Practice. Cambridge: Cambridge

Castoriadis, Cornelius. El Avance de la Insignificancia. Traducción de Alejandro Pignato. $1^{\text {a }}$ edición 1996. Buenos Aires: Eudeba, 1997.

Cherry, John. Generalization and the archaeology of the state. In: Green, David; Haselgrove, Colin; Spriggs, Matthew (eds) Social Organization and Settlement: Contributions From Anthropology, Archaeology and Geography. Oxford: British Archaeological Reports, 1978, p. 411-437.

Christ, Matthew. Legal self-help on private property in Classical Athens. The American Journal of Philology, 119, 4, 1998, p. 521-545.

Clastres, Pierre. Investigaciones en Antropología Política. Traducción de Estela Campo. $1^{\mathrm{a}}$ edición 1980. Barcelona: Gedisa Editorial, 2001.

. La Sociedad Contra el Estado. Traducción de Ana Pizarro. $1^{\text {a }}$ edición 1974. Buenos Aires: Terramar Ediciones, 2008.

Cohen, Edward. The Athenian Nation. Princeton: Princeton University Press, 2000.

Connor, Robert. The New Politicians of Fifth-Century Athens. 1st edition 1972. Indianapolis: Hackett Publishing Company, 1992.

Couvenhes, Jean-Christophe. L'introduction des archers scythes, esclaves publics, à Athènes: La date et l'agent d'un transfert culturel. In: Legras, Bernard (dir.) Transferts Culturels et Droit dans le Monde Grec et Hellénistique. Paris: Publications de la Sorbonne, 2012, p. 99-119.

De Ste. Croix, Geoffrey. La Lucha de Clases en el Mundo Griego Antiguo: De la Época Arcaica a la Conquista Árabe. Traducción de Teófilo de Lozoya. $1^{a}$ edición 1981. Barcelona: Editorial Crítica, 1988.

Detienne, Marcel. Comparar lo Incomparable: Alegato en Favor de Una Ciencia Histórica Comparada. Traducción de Marga Latorre. $1^{\text {a }}$ edición 2000. Barcelona: Ediciones Península, 2001.

. Los Griegos y Nosotros: Antropología Comparada de la Grecia Antigua. Traducción de Alfredo Iglesias Diéguez. $1^{a}$ edición 2005. Madrid: Ediciones Akal, 2007.

Easton, David. The political system besieged by the state. Political Theory, 9, 3, 1981, p. 303-325.

Ehrenberg, Victor. The Greek State. Oxford: Blackwell, 1960.

Evans, Peter; Rueschemeyer, Dietrich; Skocpol, Theda (eds) Bringing the State Back In. Nueva York: Cambridge University Press, 1985.

Faraguna, Michele. Individuo, stato e comunità. Studi recenti sulla polis. Dike. Rivista di Storia del Diritto Greco ed Ellenistico, 3, 2000, p. 217-229.

Finley, Moses. Vieja y Nueva Democracia. Traducción de Antonio Pérez-Ramos. $1^{\mathrm{a}}$ edición 1973. Barcelona: Editorial Ariel, 1979. 
. Demagogos atenienses. In: Finley, Moses (ed.) Estudios Sobre Historia Antigua. Traducción de Ramón López. $1^{\mathrm{a}}$ edición 1974. Barcelona: Akal Editor, 1981, p. 11-36.

. El Nacimiento de la Política. Traducción de Teresa Sempere. $1^{\text {a }}$ edición 1983. Barcelona: Editorial Crítica, 1986.

Forsdyke, Sarah. Slaves Tell Tales: And Other Episodes in the Politics of Popular Culture in Ancient Greece. Princeton: Princeton University Press, 2012.

Fortes, Meyer; Evans-Pritchard, Edward. Introduction. In: African Political Systems. London: Oxford University Press, 1940, p. 5-6

Gallego, Julián. La Democracia en Tiempos de Tragedia: Asamblea Ateniense y Subjetividad Política. Buenos Aires; Miño y Dávila Editores, 2003.

. Control social, participación popular y patronazgo en la Grecia clásica. Circe de Clásicos y Modernos, 12, 2008, p. 187-206.

. El patronazgo rural en la democracia ateniense. Studia Historica: Historia Antigua, 27, 2009, p. 163-175.

. La asamblea ateniense y el problema del Estado: Instauración y agotamiento de una subjetividad política. In: Campagno, Marcelo; Gallego, Julián; García Mac Gaw, Carlos (comps) El Estado en el Mediterráneo Antiguo: Egipto, Grecia, Roma. Buenos Aires: Miño y Dávila Editores, 2011, p. 181-222.

. La Pólis Griega: Orígenes, Estructuras, Enfoques. Buenos Aires: Editorial de la Facultad de Filosofía y Letras - Universidad de Buenos Aires, 2017.

Gallego, Julián; Iriarte, Ana. La tragedia ática: Política y emotividad. In: Sancho Rocher, Laura (ed.) Filosofía y Democracia en la Grecia Antigua. Zaragoza: Prensas Universitarias de Zaragoza, 2009, p. 103-126.

García, María. La Policía en Grecia: De la Polis al Estado Helenístico. Tesis doctoral. Facultad de Filología, Departamento de Filología Clásica. Madrid: Universidad Complutense de Madrid, 2006.

Gellner, Ernest. Naciones y Nacionalismos. Traducción de Javier Setó. $1^{\mathrm{a}}$ edición 1983. Buenos Aires: Alianza Editorial, 1991.

. El Arado, la Espada y el Libro: La Estructura de la Historia Humana. Traducción de Valeriano Iranzo. $1^{\text {a }}$ edición 1988. Barcelona: Ediciones Península, 1994.

Gil Fernández, Luis. Sobre la Democracia Ateniense. Madrid: Editorial Dykinson, 2009.

Glassner, Jean-Jacques. Du bon usage du concept de cité-État? Journal des africanistes, 74, 1-2, 2004, p. 35-48.

Gledhill, John. El Poder y Sus Disfraces: Perspectivas Antropológicas de la Política. Traducción de Francisco J. Ramos. $1^{\text {a }}$ edición 1999. Barcelona: Edicions Bellaterra, 2000.

Goldstone, Jack; Haldon, John. Ancient states, empires, and exploitation: Problems and perspectives. In: Morris, Ian; Scheidel, Walter (eds) The Dynamics of Ancient Empires: State Power From Assyria to Byzantium. Oxford: Oxford University Press, 2009, p. 3-29. 
Griffeth, Robert; Thomas, Carol (eds) The City-State in Five Cultures. Santa Barbara: ABC-Clio, 1981.

Griffith, Guy. Isegoria in the Assembly at Athens. In: Badian, Ernst (ed.) Ancient Society and Institutions: Studies Presented to Victor Ehrenberg on His 75th Birthday. Nueva York: Barnes \& Noble, 1967, p. 115-138.

Grinin, Leonid. Democracy and early state. Social Evolution \& History, 3, 2, 2004, p. 93-149.

Guery, Alain. L'historien, la crise et l'État. Annales. Histoire, Sciences Sociales, 52, 2, 1997, p. 233-256.

Haldon, John. The State and the Tributary Mode of Production. London: Verso Books, 1993.

Hall, Edith. The archer scene in Aristophanes' Thesmophoriazusae. Philologus, 133, 1989, p. 38-54.

Hansen, Morgens. Apagoge, Endeixis and Ephegesis against Kakourgoi, Atimoi and Pheugontes: A Study in the Athenian Administration of Justice in the Fourth Century B.C. (Odense University Classical Studies, 8). Odense: Odense University Press, 1976.

. The Athenian Ecclesia I: A Collection of Articles 1976-83. Copenhague: Museum Tusculanum Press, 1983.

. The Athenian Assembly in the Age of Demosthenes. Oxford: Blackwell, 1987.

Was Athens a Democracy? Popular Rule, Liberty and Equality in Ancient and Modern Political Thought. Copenhagen: Royal Danish Academy of Sciences and Letters, 1989a.

. The Athenian Ecclesia II: A Collection of Articles 1983-89. Copenhagen: Museum Tusculanum Press, 1989b.

. The Athenian Democracy in the Age of Demosthenes: Structure, Principles, and Ideology. Translation by J.A. Cook. Oxford: Blackwell, 1991.

Introduction: The Polis as a Citizen-State. In: The Ancient Greek City-State. Copenhagen: Royal Danish Academy of Sciences and Letters, 1993, p. 7-29.

. The ancient Athenian and the modern liberal view of liberty as a democratic ideal. In: Ober, Josiah; Hedrick, Charles (eds) Dêmokratia: A Conversation on Democracies, Ancient and Modern. Princeton: Princeton University Press, 1996, p. 91104.

. Polis and City-State. An Ancient Concept and its Modem Equivalent. Copenhagen: Royal Danish Academy of Sciences and Letters, 1998.

. (ed.) A Comparative Study of Thirty City-State Cultures: An Investigation Conducted by the Copenhagen Polis Centre. Copenhagen: Kongelige Danske Videnskabernes Selskab, 2000.

. Was the polis a state or a stateless society? In: Nielsen, Thomas (ed.) Even More. Studies in the Ancient Greek Polis. Stuttgart: Franz Steiner Verlag, 2002, p. 1747.

- (ed.) A Comparative Study of Six City-State Cultures: An Investigation Conducted by the Copenhagen Polis Centre. Copenhagen: Kongelige Danske Videnskabernes Selskab, 2002. 
Harris, Edward. Who enforced the law in Classical Athens? In: Symposion 2005: Vorträge zur griechischen und hellenistischen Rechtsgeschichte (Salerno, 14-18 September 2005). Vienna: Verlag der Österreichischen Akademie der Wissenschaften, 2007, p. 159-176

Press, 2013.

The Rule of Law in Action in Democratic Athens. Oxford: Oxford University

Herman, Gabriel. Ritualized Friendship and the Greek City. Cambridge: Cambridge University Press, 1987.

. How violent was Athenian society? In: Osborne, Robin; Hornblower, Simon (eds) Ritual, Finance, Politics. Athenian Democratic Accounts Presented to David Lewis. Oxford: Oxford University Press, 1994, p. 99-117.

. Morality and Behavior in Democratic Athens: A Social History. Cambridge: Cambridge University Press, 2006.

Hobbes, Thomas. Leviatán o la Materia, Forma y Poder de Una República Eclesiástica y Civil. Traducción de Manuel Sánchez Sarto. $1^{a}$ edición 1651. México: Fondo de Cultura Económica, 1980.

Hunter, Victoria. Policing Athens: Social Control in the Attic Lawsuits, 420-32O B.C. Princeton: Princeton University Press, 1994.

Ismard, Paulin. The single body of the city: Public slaves and the question of the Greek state. Annales. Histoire, Sciences Sociales, 69, 3, 2014, p. 505-32.

Paris: Seuil, 2015

La Démocratie Contre les Experts: Les Esclaves Publics en Grèce Ancienne.

Jacob, Oscar. Les Esclaves Publics à Athènes. Lieja: Champion, 1928.

Jessop, Bob. Crisis del Estado de Bienestar: Hacia una Nueva Teoría del Estado y Sus Consecuencias Sociales. Traducción de Alberto S. Sarmiento. Santa Fe de Bogotá: Siglo del Hombre Editores - Universidad Nacional de Colombia, 1999.

Kennedy, George. The Art of Persuasion in Greece. Princeton: Princeton University Press, 1963.

Knox, Ronald. «So mischievous a beaste»? The Athenian demos and its treatment of its politicians. Greece \& Rome, 32, 2, 1985, p. 132-61.

Lanni, Adriaan. Public and private in classical Athenian legal enforcement. In: Ando, Clifford; Rüpke, Jörg (eds) Public and Private in Ancient Mediterranean Law and Religion. Berlin: De Gruyter, 2015, p. 37-52.

Larran, Francis. Le Bruit Qui Vole. Histoire de la Rumeur et de la Renommée en Grèce Ancienne. Mirail: Presses Universitaires de Toulouse-Le Mirail, 2011.

Laslett, Peter. The face to face society. In: Laslett, Peter (ed.) Philosophy, Politics and Society: A Collection. Oxford: Basil Blackwell, 1956, p. 157-84.

Lefort, Claude. La obra de Clastres. In: Abensour, Miguel (comp.) El Espíritu de las Leyes Salvajes: Pierre Clastres o Una Nueva Antropología Política. Traducción de Carina Battaglia. $1^{\text {a }}$ edición 1987. Buenos Aires: Ediciones del Sol, 2007, p. 279-315.

Lenin, Vladimir. El Estado y la Revolución. Traducción del Grupo de Traductores de la Fundación Federico Engels. $1^{\text {a }}$ edición 1917. Madrid: Fundación Federico Engels, 1997. 
Lewis, John. Isegoria at Athens: When did it begin? Historia: Zeitschrift für Alte Geschichte, 20, 2/3, 1971, p. 129-40.

Lewkowicz, Ignacio. Pensar sin Estado: La Subjetividad en la Era de la Fluidez. Buenos Aires: Paidós, 1994.

Lintott, Andrew, Violence, Civil Strife and Revolution in the Classical City, 750-330 $B C$. Baltimore: John Hopkins University Press, 1982.

Lissarrague, François. L'Autre Guerrier: Archers, Peltastes, Cavaliers dans l'Imagerie Attique. Paris \& Roma: Editions La Découverte, 1990.

Longo, Oddone. Ad Alceo 112.10 L.-P.: Per la Storia di un Topos. Bollettino dell'Istituto di Filologia Greca, 1, 1974, p. 211-28.

87-113. . La polis, le mura, le navi (Tucidide VII, 77,7). Quaderni di Storia, 1, 1975, p.

Lonis, Raoul. Astu et Polis. Remarques sur le vocabulaire de la ville et de l'État dans les inscriptions attiques du V au milieu du II s. av. J.-C. Ktèma: Civilisations de l'Orient, de la Grèce et de Rome Antiques, 8, 1983, p. 95-109.

López Barja De Quiroga, Pedro. La ciudad antigua no era un Estado. In: Dell'Elicine, Eleonora; Francisco, Héctor; Miceli, Paola; Morin, Alejandro (coords) Pensar el Estado en las Sociedades Precapitalistas: Pertinencia, Límites y Condiciones del Concepto de Estado. Los Polvorines: Universidad Nacional de General Sarmiento, 2012, p. 79-92.

Loraux, Nicole. L'Invention d'Athènes: Histoire de l'Oraison Funèbre dans la "Cité Classique». Paris: Payot, 1993.

. Notas sobre el uno, el dos y lo múltiple. In: Abensour, Miguel (comp.) El Espíritu de las Leyes Salvajes: Pierre Clastres o Una Nueva Antropología Política. Traducción de Carina Battaglia. $1^{\text {a }}$ edición 1987. Buenos Aires: Ediciones del Sol, 2007, p. 243-64.

La Guerra Civil en Atenas. La Política Entre la Sombra y la Utopía. Traducción de Ana Iriarte. $1^{\text {a }}$ edición 2005. Madrid: Akal Editor, 2008.

Macdowell, Douglas. The Law in Classical Athens. Nueva York: Cornell University Press, 1978.

Mann, Michael. Las Fuentes del Poder Social: I. Una Historia del Poder Desde los Comienzos Hasta 1760 d.C. Traducción de Fernando Santos Fontenla. $1^{\text {a }}$ edición 1986. Madrid: Alianza Editorial, 1991.

Manville, Philip. Toward a new paradigm of Athenian citizenship. In: Boegehold, Alan; Scafuro, Adele (eds) Athenian Identity and Civic Ideology. Baltimore: The John Hopkins University Press, 1994, p. 21-33.

Meier, Christan. Introducción a la Antropología Política de la Antigüedad Clásica. Traducción de José Barrales Valladares. $1^{\text {a }}$ edición 1984. México: Fondo de Cultura Económica, 1985.

Millett, Paul. Patronage and its avoidance in ancient Athens. In: Wallace-Hadrill, Andrew (ed.) Patronage in Ancient Society. Londres: Routledge, 1989, p.15-47.

Miyazaki, Makoto. Public coercive power of the Greek polis. On recent debate. Bulletin of the Institute for Mediterranean Studies, 5, 2007, p. 87-100. 
Molho, Anthony; Raaflaub, Kurt A.; Emlen, Julia (eds) City-States in Classical Antiquity and Medieval Italy. Ann Arbor: The University of Michigan Press, 1992.

Morris, Ian. Burial and Ancient Society. The Rise of Greek City-State. Cambridge: Cambridge University Press, 1987.

. The early polis as city and state. In: Rich, John; Wallace-Hadrill, Andrew (eds) City and Country in the Ancient World. Londres: Routledge, 1991, p. 25-57.

. An archaeology of inequalities? The Greek city-states. In: Nichols, Deborah; Charlton, Thomas (eds) The Archaeology of City-States: Cross-Cultural Approaches. Washington: Smithsonian Institution Press, 1997, p. 91-105.

The greater Athenian state. In: Morris, Ian; Scheidel, Walter (eds) The Dynamics of Ancient Empires: State Power from Assyria to Byzantium. Oxford: Oxford University Press, 2009, p. 99-177.

Musti, Domenico. Demokratía. Orígenes de Una Idea. Traducción de Pepa Linares. $1^{\text {a }}$ edición 1995. Madrid: Alianza Editorial, 2000.

Nakategawa, Yoshio. Isegoria in Herodotus. Historia: Zeitschrift für Alte Geschichte, 37, 3, 1988, p. 257-275.

Nichols, Deborah; Charlton, Thomas (eds) The Archaeology of City-States: CrossCultural Approaches. Washington: Smithsonian Institution Press, 1997.

Nietzsche, Friedrich. Así Habló Zaratustra. Traducción de Carlos Vergara. $1^{\text {a }}$ edición 1883-1891. Buenos Aires: Edaf, 1999.

Ober, Josiah. Mass and Elite in Democratic Athens: Rhetoric, Ideology and the Power of the People. Princeton: Princeton University Press, 1989.

. The Athenian Revolution. Essays on Ancient Greek Democracy and Political Theory. Princeton: Princeton University Press, 1996.

. Quasi-rights: Participatory citizenship and negative liberties in democratic Athens. Social Philosophy and Policy Foundation, 17, 2000, p. 27-60.

Offe, Claus. Contradicciones en el Estado del Bienestar. Traducción de Antonio Escohotado. $1^{\text {a }}$ edición 1984. Madrid: Alianza Editorial, 1990.

Ohmae, Kenichi. The End of the Nation State: The Rise of Regional Economies. Nueva York: The Free Press, 1995.

Oliveira Gomes, Claudia de. La Cité Tyrannique. Histoire Politique de la Grèce Archaïque. Rennes: Presses Universitaires de Rennes, 2007.

Osborne, Robin. Demos: The Discovery of Classical Attika. Cambridge: Cambridge University Press, 1985.

Padgug, Robert. Clases y sociedad en la Grecia clásica. In: AA.VV. El Marxismo y los Estudios Clásicos. Traducción de Ramón López Domech. $1^{\text {a }}$ edición 1975. Madrid: Akal Editor, 1981, p.73-103

Paiaro, Diego. Las ambigüedades del Estado en la democracia ateniense: Entre la libertad y la coacción. In: Campagno, Marcelo; Gallego, Julián; García Mac Gaw, Carlos (comps) El Estado en el Mediterráneo Antiguo: Egipto, Grecia, Roma. Buenos Aires: Miño y Dávila Editores, 2011a, p. 223-42.

- Las reformas de Solón y los límites de la coacción extraeconómica en la Atenas arcaica. Sociedades Precapitalistas: Revista de Historia Social, 1, 1, 2011b. 
. Ándres gàr pólis. Algunas reflexiones acerca de los debates recientes en torno a la estatalidad de la ciudad griega antigua a la luz del caso ateniense. In: Dell'Elicine, Eleonora; Francisco, Héctor; Miceli, Paola; Morin, Alejandro (coords) Pensar el Estado en las Sociedades Precapitalistas: Pertinencia, Límites y Condiciones del Concepto de Estado. Los Polvorines: Universidad Nacional de General Sarmiento, 2012a, p. 51-77.

. Relaciones de dependencia en la Atenas clásica, entre la explotación y la dominación. Trabajos y comunicaciones, 38, 2012b, p. 153-83.

. Defendiendo la libertad del dêmos. Control popular y ostracismo en la democracia ateniense. Anales de Historia Antigua, Medieval y Moderna, 44, 2012c, p. $33-62$.

. Salvajes en la ciudad clásica. Pierre Clastres y la antropología política de la democracia ateniense. In: Campagno, Marcelo (ed.) Pierre Clastres y las Sociedades Antiguas. Buenos Aires: Miño y Dávila Editores, 2014, p. 119-40

Parker, Geoffrey. Sovereign City: The City-State Through History. Londres: Reaktion Books, 2004.

Picazo, Marisa. Reprimir a los «reyes devoradores de dones»: Mecanismos de control social en la Grecia antigua. In: Cid López, Rosa; García Fernández, Estela (eds) Debita Verba: Estudios en Homenaje al Profesor Julio Mangas Manjarrés (Vol. I). Oviedo: Ediciones de la Universidad de Oviedo, 2013, p. 513-23.

Piérart, Marcel. À propos de l'élection des stratèges athéniens. Bulletin de Correspondance Hellénique, 98, 1, 1974, p. 125-46.

Plácido, Domingo. «Nombres de libres que son esclavos...» (Pólux, III, 82). In: Garrido-Hory, Marguerite (coord.) Esclavos y Semilibres en la Antigüedad Clásica. Madrid: Universidad Complutense de Madrid, 1989, p. 55-79.

. La Sociedad Ateniense: La Evolución Social en Atenas Durante la Guerra del Peloponeso. Barcelona: Editorial Crítica, 1997.

. Liturgias, evergetismo y mistoforía: Los modos de redistribución de la ciudad democrática. In: Marco Simón, Francisco; Pina Polo, Francisco; Remesal Rodríguez, José (eds) Repúblicas y Ciudadanos: Modelos de Participación Cívica en el Mundo Antiguo. Barcelona: Universidad de Barcelona, 2006, p. 41-54.

Plácido, Domingo; Fórnis, César. Evergetismo y relaciones clientelares en la sociedad ateniense del siglo IV a.C. Dialogues D'histoire Ancienne, 37, 2, 2011, p. 19-47.

Plassart, Agnés. Les archers d'Athènes. Revue des Études Grecques, 26, 117, 1913, p. 151-213.

Portinaro, Pier. Estado: Léxico de Política. Traducción de Heber Cardoso. $1^{\mathrm{a}}$ edición 1999. Buenos Aires: Ediciones Nueva Visión, 2003.

Pritchard, David. The archers of classical Athens. Greece \& Rome, 65, 1, 2018, p. 86102.

Raaflaub, Kurt. The Discovery of Freedom in Ancient Greece. 1st edition 1985. Chicago: The University of Chicago Press, 2004.

Radcliffe-Brown, Alfred. Preface. In: Fortes, Meyer; Evans-Pritchard, Edward. (eds) African Political Systems. Londres: Oxford University Press, 1940, p. xi-xxiii. 
Rahe, Paul. Republics Ancient and Modern: Volume I. The Ancien Régime in Classical Greece. Chapel Hill: The University of North Carolina Press, 1994.

Reiss, Werner. Private violence and state control. In: Brélaz, Cédric; Ducrey, Pierre (eds) Sécurité Collective et Orde Public dans les Sociétés Anciennes. Ginebra: Fondation Hardt, 2007, p. 49-101.

Requena, Mariano. ¿Se puede hablar de un «patronazgo estatal»? Liturgias y misthophoría en la Atenas Clásica. Sociedades Precapitalistas: Revista de Historia social, 2, 2, 2013.

Rhodes, Peter. A Commentary on the Aristotelian Athenaion Politeia. Oxford: Clarendon Press, 1981.

. Problems in Athenian eisphora and liturgies. American Journal of Ancient History, 7, 1, 1982, p. 1-19.

. The «Acephalous» Polis? Historia: Zeitschrift für Alte Geschichte, 44, 2, 1995, p. 153-67.

- Who ran democratic Athens? In: Flensted-Jensen, Pernille; Nielsen, Thomas; Rubinstein, Lene (eds) Polis \& Politics. Studies in Ancient Greek History Presented to Mogens Herman Hansen on His Sixtieth Birthday. Copenhagen: Museum Tusculanum Press. 2000, p. 465-77.

Rihll, Tracey. War, slavery and settlement in early Greece. In: Rich, John; Shipley, Graham (eds) War and Society in the Greek World. London: Routledge, 1993, p. 77107.

Roberts, Jennifer. Accountability in Athenian Government. Wisconsin: University of Wisconsin Press, 1982.

Rosenberg, Justin. The Empire of Civil Society: A Critique of the Realist Theory of International Relations. London: Verso, 1994.

Routledge, Bruce. Archaeology and State Theory: Subjects and Objects of Power. New York/London: Bloomsbury, 2014.

Runciman, Garry. Doomed to extinction: The polis as an evolutionary dead end. In: Murray, Oswyn; Price, Simon (eds) The Greek City: From Homer to Alexander. Oxford: Oxford University Press, 1990, p. 347-67.

Ruzé, Françoise. Eunomia. À la Recherche de l'Équité. Paris: De Boccard, 2003.

Sahlins, Marshall. Las Sociedades Tribales. Traducción de Francisco Payarols. $1^{\text {a }}$ edición 1968. Barcelona: Editorial Labor, 1972.

Sakellariou, Michael. The Polis-State: Definition and Origin. Atenas: Research Center for Greek and Roman Antiquity, 1989.

Sancho Rocher, Laura. Un Proyecto Democrático: La Política en la Atenas del Siglo $V$. Zaragoza: Egido Editorial, 1997.

. Entre tradición y revolución: La fundación de la demokratía. In: Sancho Rocher, Laura (ed.) Filosofía y Democracia en la Grecia Antigua. Zaragoza: Prensas Universitarias de Zaragoza, 2009, p. 15-39.

. Comunidad e individuo en la democracia antigua. Naturaleza, ley y sociedad. Circe de Clásicos y Modernos, 15, 2. 2011a, p. 133-57. 
Comunidad e individuo en la democracia antigua (II). Garantías del individuo y espacio privado en la democracia ateniense. In: Campagno, Marcelo; Gallego, Julián; García Mac Gaw, Carlos (comps) El Estado en el Mediterráneo Antiguo: Egipto, Grecia, Roma. Buenos Aires: Miño y Dávila Editores, 2011b, p. 24366.

Sanderson, Stephen. Social Transformations: A General Theory of Historical Development. Lanham: Rowman \& Littlefield Publishers, 1999.

Sassen, Saskia. Losing Control? Sovereignty in an Age of Globalization. New York: Columbia University Press, 1996.

Scheidel, Walter. Studying the State. In: Bang, Peter; Scheidel, Walter (eds) The Oxford Handbook of the State in the Ancient Near East and Mediterranean. Nueva York: Oxford University Press, 2013, p. 5-57.

Silver, Morris. Reinstating classical Athens: The production of public order in an Ancient Community. Journal on European History of Law, 6, 2015, p. 3-17.

Sinclair, Robert. Democracia y Participación en Atenas. Traducción de Martín-Miguel Rubio Esteban. $1^{\text {a }}$ edición 1988. Madrid: Alianza Editorial, 1999.

Solana Dueso, José. Protágoras de Abdea. Dissoi Logoi. Textos Relativistas. Madrid: Ediciones Akal, 1996.

Sørensen, Georg. La Transformación del Estado: Más Allá del Mito del Repliegue. Traducción de Ramón Cotarelo. $1^{a}$ edición 2003. Valencia: Tirant lo Blanch, 2010.

Starr, Chester. Individual and Community: The Rise of the Polis, 80o-50o B.C. Nueva York: Oxford University Press, 1986.

. The Birth of Athenian Democracy: The Assembly in the Fifth Century B.C. New York: Oxford University Press, 1990.

Strange, Susan. The Retreat of the State: The Diffusion of Power in the World Economy. Cambridge: Cambridge University Press, 1996.

Tamiolaki, Melina. A citizen as a slave of the state? Oligarchic perceptions of democracy in Xenophon. Greek, Roman \& Byzantine Studies, 53, 2013, p. 31-50.

Tilly, Charles. Coerción, Capital y los Estados Europeos (990-1990). Traducción de Eva Rodríguez Halfter. $1^{\text {a }}$ edición 1990. Buenos Aires: Alianza Editorial, 1993.

Tuci, Paolo. Arcieri sciti, esercito e democrazia nell'Atene del V secolo A.C. Aevum, 78, 1, 2004, p. 3-18.

. Gli arcieri sciti nell'Atene del V ecolo A.C. In: Bertinelli, Maria; Donati, Angela (eds) Il Cittadino, lo Straniero Il Barbaro fra Integrazione et Emarginazione nell'Antichita: Atti del I Incontrao Internazionale du Storia Antica (Genova 22-24 maggio 2003). Roma: Giorgio Bretschneider Editore, 2005, p. 375-89.

Van Der Vliet, Edward. Polis. The problem of statehood. Social Evolution \& History, 4, 2, 2005, p. 120-50.

. The early state, the polis and state formation in early Greece. Social Evolution \& History, 7, 1, 2008, p. 197-221.

Vernant, Jean-Pierre. Los Orígenes del Pensamiento Griego. Traducción de Marino Ayerra. $1^{\text {a }}$ edición 1962. Barcelona: Editorial Paidós, 1992. 
Atravesar Fronteras. Entre Mito y Política II. Traducción de Hugo Francisco Bauzá. $1^{\text {a }}$ edición 2004. Buenos Aires: Fondo de Cultura Económica, 2008. Weber, Max. Economía y Sociedad: Esbozo de Sociología Comprensiva. Traducción de José Medina Echavarría, Juan Roura Farella, Eugenio Ímaz, Eduardo García Máynes y José Ferrater Mora. $1^{\mathrm{a}}$ edición 1922. México: Fondo de Cultura Económica, 1964.

Weiss, Linda. The Myth of the Powerless State: Governing the Economy in a Global Era. Ithaca: Cornell University Press, 2010.

Wood, Ellen M. Demos versus «We, the People»: Freedom and democracy ancient and modern. In: Ober, Josiah; Hedrick, Charles (eds) Demokratia: A Conversation on Democracies, Ancient and Modern. Princeton: Princeton University Press, 1996, p. 121-37.

Democracia Contra Capitalismo: La Renovación del Materialismo Histórico. Traducción de Adriana Hierro. $1^{\mathrm{a}}$ edición 1995. México: Siglo Veintiuno Editores, 2000.

Zuiderhoek, Arjan. The Ancient City. Cambridge: Cambridge University Press, 2017. 